\title{
Symposium review: Scientific assessment of affective states in dairy cattle*
}

\author{
Thomas Ede, Benjamin Lecorps, Marina A. G. von Keyserlingk, and Daniel M. Weary ${ }^{\dagger}$ \\ Animal Welfare Program, Faculty of Land and Food Systems, University of British Columbia, Vancouver, BC, Canada V6T 1 Z6
}

\section{ABSTRACT}

Affective states, which refer to feelings or emotions, are a key component of animal welfare, but these are also difficult to assess. Drawing upon a body of theoretical and applied work, we critically review the scientific literature on the assessment of affective states in animals, drawing examples where possible from research on dairy cattle, and highlighting the strengths and weaknesses of scientific methods used to assess affective states in animals. We adopt the "valence/arousal" framework, describing affect as a 2-dimensional space (with valence referring to whether an experience is positive or negative, and arousal referring to the intensity of the experience). We conclude that spontaneous physiological and behavioral responses typically reflect arousal, whereas learned responses can be valuable when investigating valence. We also conclude that the assessment of affective states can be furthered using mood assessments and that the use of drug treatments with known emotional effects in humans can be helpful in the assessment of specific affective states in animals. Key words: cognition, motivation, preference, aversion, anhedonia

\section{INTRODUCTION}

A key component of animal welfare is the animal's affective state; in other words, how it feels. Affective states can be negative, like pain and fear, or positive, like pleasure and happiness (Boissy et al., 2007; Webb et al., 2019). Affective states are subjective by nature, making them out of reach of direct assessment. As Panksepp (2005) puts it, "There is no mind scope, and may never be, that can directly monitor any psychological process." The "hard problem" (Chalmers, 1995) of studying the subjective experience of emotions is not limited to animals; it is also a critical and controversial

Received January 17, 2019.

Accepted June 29, 2019.

*Presented as part of the Animal Behavior and Well-Being Platform Session: Assessment of Affective States of Dairy Cattle at the ADSA

Annual Meeting, Knoxville, Tennessee, June 2018.

†Corresponding author: dan.weary@ubc.ca topic in the human literature. With humans, researchers can ask (most) patients how they feel, providing a type of gold standard for research on competent, verbal humans. Given that this approach is not applicable to dairy cows (or other animals), the challenge is to identify useful surrogate measures.

As David Fraser puts it: "There is no simple English word to capture the class of concepts such as 'pleasure,' 'pain,' 'suffering,' and 'happiness.' They are sometimes called 'feelings,' but that term seems too insubstantial for states like pain and suffering. They are sometimes called 'emotions,' but emotions do not include states like hunger and thirst. Perhaps the most accurate, if rather technical, term is affective states, a term that refers to emotions and other feelings that are experienced as pleasant or unpleasant rather than hedonically neutral" (Fraser, 2008).

This quote serves to illustrate one component of affect: valence (i.e., whether something is experienced as positive or negative). Valence is of great relevance to animal welfare because minimizing negative affective states and maximizing positive ones is key to improving welfare (Fraser and Duncan, 1998). However, limiting affect to valence might be inadequate. Borrowing from the human literature (Bradley and Lang, 1994; Barrett, 1998), Mendl et al. (2010) provided a framework that integrated valence and arousal (relating to the intensity of the affective state). For example, fearfulness and sadness are both negative states but sadness is typically lower in arousal (Figure 1). As a further illustration, when humans were asked to position their affective reactions to images, they rated a cemetery as negativelow arousal, an aimed gun as negative-high arousal, a rollercoaster as positive-high arousal, and a cow as positive-low arousal (Bradley and Lang, 1994). In this review, we use the words "affect," "emotion," and "feeling" synonymously (as defined by Mendl et al., 2010) and avoid claims about consciousness or self-awareness.

Although we adopted the 2-dimensional arousal/ valence framework for this review, we acknowledge that it might be incomplete; authors have mentioned a third dimension that includes the control (or agency) over the experience (Bradley and Lang, 1994; Warriner et al., 2013). Additionally, dimensions might be different from the continuous spectra assumed here. For example, 
some have argued that positive and negative valences are 2 distinct processes rather than 2 ends of a single continuum (Fraser and Duncan, 1998; Shriver, 2014).

Affective states are 1 of the 3 commonly discussed components of animal welfare, the remaining 2 being natural living and physical health (Fraser et al., 1997). As described by Webb et al. (2019), natural living and physical health belong to the "assumed" aspects of welfare (as we assume natural environments and good health to improve welfare), whereas affective states belong to the "apparent" aspect (as this directly relates to the animal's experience). This review will focus on affective states, because of their importance to welfare and because of the challenges in developing assessment methods for these states. Moreover, practical efforts to address welfare problems typically require that we know the specific affective state of concern (e.g., is the cow experiencing pain or fear, or both), if we are to develop methods of prevention or treatment. Thus, where possible, we also discuss whether different measures can be useful in drawing inferences regarding specific affective states.

The objective of this critical review was to assess the strengths and weaknesses of scientific methods used to assess affective states in animals. We discuss inferences regarding physiological and spontaneous behavioral responses, especially regarding arousal. We also discuss what inferences regarding valence can be drawn from studies of learned behaviors. We consider how affective states contribute to mood (i.e., the sum

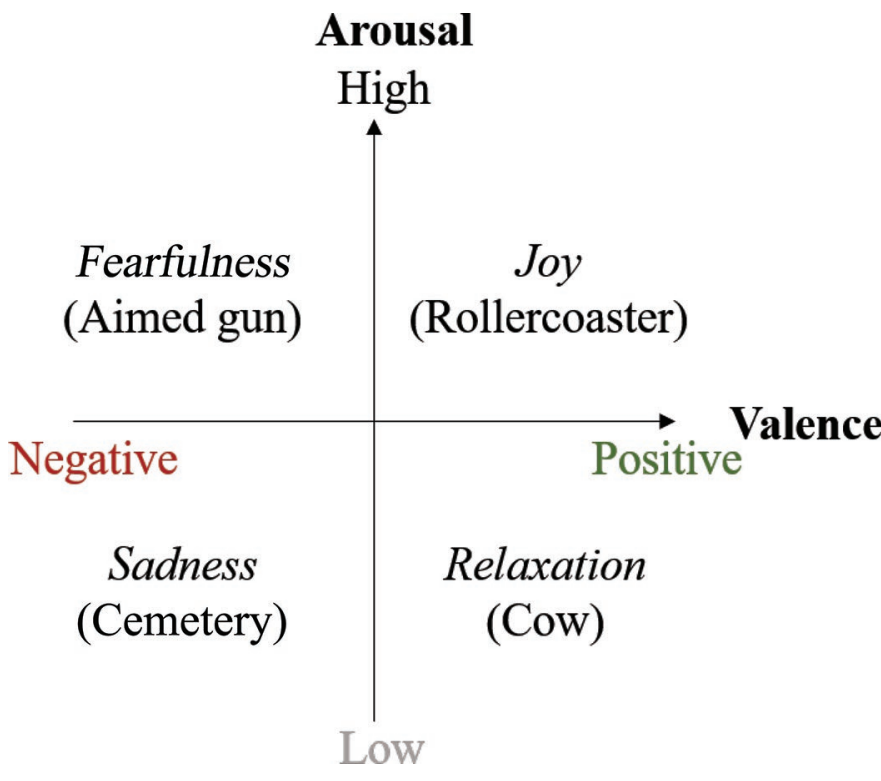

Figure 1. Theoretical framework of affect including 2 components: valence and arousal. Words in italics are examples of affective states in each quadrant, adapted from Barrett (1998) and Mendl et al. (2010). Words in parentheses refer to examples from Bradley and Lang (1994). of affective states; Boissy and Lee, 2014), how mood itself can be assessed, and finally how experimental treatments using drugs can be used to draw inferences regarding specific affective states. Where possible, we use examples of research on dairy cattle but also refer to work on other species to provide historical context and note the translatability of studies to dairy cattle and highlight approaches that have not yet been applied to cattle. Our examples with dairy cattle focus on cows and calves, as little relevant research has been published addressing this issue in other types of dairy cattle (e.g., dairy bulls).

\section{SPONTANEOUS RESPONSES}

\section{Physiological Responses}

Stress has been the focus of much research on farm and laboratory animal welfare (Broom, 1988, 1991; Jensen and Toates, 1997; Veissier and Boissy, 2007), leading to an interest in measures related to the activation of the hypothalamic-pituitary-adrenal (HPA) axis and sympathetic nervous system (SNS) in response to stressful events. The term "stress" can sometimes imply a negative experience. A broader definition of stress - that we adopt in this review -includes reactions to all challenges to homeostasis (Rushen, 1986; Mellor et al., 2000). In the following section, we will argue that responses related to activation of the HPA and SNS are of most value as nonspecific indicators of arousal. Stress responses generally show some proportionality to challenge intensity (Mellor et al., 2000), but the nonspecific nature of these responses means that thorough knowledge of the subjects' circumstances and experiences preceding the assessment (e.g., housing, interactions with pen mates, handling) is required to inform inferences regarding valence, let alone the specific emotion of interest.

Stress responses have been studied in dairy cattle on a wide array of scales, from hormones such as adrenaline (Hopster et al., 2002) and cortisol (Stock et al., 2013), to organ systems including circulatory (Kovács et al., 2015) and respiratory (Rizk et al., 2012) responses at the organ system level, and whole-animal measures such as activity (Webb et al., 2017). Reviewing each of these responses is beyond the scope of this review. Instead, we focus on just 4 responses (cortisol, heart rate variability, eye/nose temperature, and eye white), based on their prevalence in the cattle literature and our personal experience.

Cortisol. Cortisol and other measures related to activation of the HPA axis have often been used in studies of affect in cattle, including studies on painful procedures (Adcock and Tucker, 2018). For example, 
in one review on cattle dehorning (Stock et al., 2013), the word "cortisol" was mentioned 275 times (in comparison, "adrenaline" and "ACTH" were mentioned 4 and 3 times, respectively). Plasma cortisol as an index is most commonly described, but sampling from milk (Verkerk et al., 1998), saliva (González et al., 2010), hair (Burnett et al., 2014), urine (Redbo, 1993), and feces (Palme et al., 2000) have been mentioned.

Elevated cortisol levels have been observed in calves following dehorning (Stilwell et al., 2010), castration (Fisher et al., 1996), and branding (SchwartzkopfGenswein et al., 1997a). Changes in plasma cortisol concentration are sensitive to pain mitigation strategies; for example, the use of a local anesthetic (lidocaine) on the cornual nerve virtually eliminates the cortisol peak response observed in the $2 \mathrm{~h}$ following horn amputation in calves (Stafford and Mellor, 2005a). Moreover, the cortisol increase usually observed as local anesthesia diminishes is reduced by the use of postoperative analgesics (Stafford and Mellor, 2011). Similar responses have been observed after castration procedures (Stafford and Mellor, 2005b).

However, the association between cortisol and pain is imperfect. For example, Coetzee et al. (2008) found no differences in cortisol between calves that had been castrated (without anesthesia or analgesia) and uncastrated calves. This example reveals a vulnerability of cortisol measures to ceiling effects; in this case, it is likely that other events associated with the surgery (e.g., restraint, blood sampling) were sufficiently stressful that animals showed maximal cortisol responses, leaving no room to detect an effect of pain. Other work has shown that cortisol responses can be brief (with differences detectable for only a few hours after the procedure) even when behavioral differences indicative of pain persist for weeks (Thüer et al., 2007). Thus, cortisol measures may be most relevant for the acute phase after a painful event but insensitive to longerterm effects. In addition, individuals typically display a decrease in cortisol responses with repeated exposure to a stressful event (i.e., the cortisol habituation response; Andrade et al., 2001; Solano et al., 2004; Wüst et al., 2005; Wong et al., 2010). Finally, it is important to note that the delay between a painful event and a change in cortisol levels makes this measure insensitive during the first few minutes after a procedure (Mellor and Stafford, 2000).

Cortisol is not specific to negative events; although not studied in cattle, elevated levels of corticosteroids have been observed in positive situations such as sexual stimulation in stallions and rats (Szechtman et al., 1974; Colborn et al., 1991), voluntary exercise in mice and rats (Stranahan et al., 2008), and exposure to an enriched environment in chickens (Solomon, 1997).
Cortisol responses are also dependent upon learning and coping capacities (Rushen, 1986), meaning that higher levels could reflect a more novel and unpredictable environment, but not necessarily a negative one.

In summary, measures linked to the activation of the HPA axis reflect an increased demand of resources from the organism. In some cases (such as in the absence of ceiling effects or outside the response duration), such measures may relate to arousal. The nonspecific nature of this response means contextual factors must be considered, including the animal's previous experiences, before drawing inferences regarding valence. Inferences regarding what specific affective state the animal is experiencing will generally be impossible without the use of drug treatments, as discussed later in this paper. See Rushen (1986) and Mellor et al. (2000) for a more detailed discussion of the strengths and limitations of using evidence of HPA axis activation to draw inferences about pain and other affective states.

Heart Rate Variability. Heart rate (HR) was used in early studies of stress in humans (Lazarus et al., 1963) and animals, including work on cows examining the effects of heat stress, dehorning, and electric shocks published in the 1950s (Graf and Petersen, 1953; Bianca, 1958). These intuitively negative events were associated with a rise in HR but so was any increase in physical activity (Graf and Petersen, 1953).

More recently, heart rate variability (HRV) has been suggested as a more sensitive measure to characterize cardiac variations associated with stress (Montebugnoli et al., 2004). Heart rate variability is based on time interval irregularities between heart beats and is thought to reflect the balance between the 2 divisions of the autonomic nervous system: sympathetic and parasympathetic (Bootsma et al., 1994; Camm et al., 1996; Berntson et al., 1997). Some authors consider a balance toward the sympathetic system (thought to result in a low HRV) to correspond to the "fight or flight" response, whereas a balance toward the parasympathetic system (thought to be associated with a high HRV) to be the "rest and digest" phase (Müller et al., 2017). The idea that HRV reflects autonomic control is based on animal and human studies blocking and amplifying either or both branches of the autonomic system and observing the resulting cardiovascular variability (Parati et al., 2006). However, no consensus has been reached on the suitability of such measures and their use remains debated (Parati et al., 2006; Billman, 2011, 2013). The trend in human medical studies to use HRV to study diseases and mental states (Langewitz and Rüddel, 1989; Kristal-Boneh et al., 1995; Gorman and Sloan, 2000) may have increased the popularity of this measure in farm animal research (von Borell et al., 2007; Kovács et al., 2014). 
Decreased HRV has been detected in dairy calves during social isolation, dummy teat removal, and hot-iron disbudding (Stewart et al., 2009; Clapp et al., 2015). Cows receiving transrectal palpation by students also showed decreased HRV (Giese et al., 2018). Decreased HRV has been observed immediately after dehorning without local anesthetics (Stewart et al., 2009), indicating the potential to use HRV to investigate immediate responses. However, inconsistencies have been noted between studies and depending on the HRV measure chosen (Stewart et al., 2009). The practical difficulties of long-term HRV data collection on cows have limited our knowledge of longer-term effects of procedures on HRV (Kovács et al., 2014). One study showed a decrease in HRV up to $48 \mathrm{~h}$ after dehorning (Clapp et al., 2015), but in that study the calves were exposed to multiple stressors, making it difficult to draw specific inferences.

Several results undermine the idea that decreased HRV is reliably associated with pain or other negative affective states. For example, marked parasympathetic dominance has been found in calves following castration without anesthesia (Stewart et al., 2010) and in lame cows (Kovács et al., 2015). Because castrated and lame animals are expected to be less active (to avoid painful stimulation), this raises the concern that HRV (like HR) may be more related to physical activity rather than to emotional state. Indeed, HRV parameters shift toward sympathetic dominance simply when healthy animals stand up (Hagen et al., 2005), suggesting that activity differences can confound interpretation of HRV.

The study of HRV in dairy cows (and farm animals in general) has focused on negative events, including disease, veterinary procedures, stressful handling, weaning, and isolation (Kovács et al., 2014). To our knowledge, no study has investigated HRV in cows during a positive event, making it difficult to judge whether HRV responses are specific to negative affect. In humans, higher HRV is associated with calmness, cheerfulness, and subjective well-being (Geisler et al., 2010), as well as with disgust and sadness (Kreibig, 2010). Lower HRV has been associated with daily worry (Brosschot et al., 2007) and with happiness (Kreibig, 2010), and the activation of the sympathetic nervous system has also been associated with sexual arousal (Meston, 2000).

Finally, major concerns have been raised regarding the influence of HR on HRV. Monfredi et al. (2014) and Kazmi et al. (2016) showed a nonlinear inverse relationship between HR and HRV (i.e., variability in HR decreases as HR increases), implying that HRV might simply be an indirect measure of HR (Monfredi et al., 2014). The latter authors indicated that it is possible to control for the effect of HR on HRV with a nonlinear correction. Unfortunately, none of the cattle studies previously mentioned used this correction. In summary, the results reviewed above suggest that HRV may be seen as a nonspecific indicator of arousal, with little basis for inferences regarding affective valence, let alone any specific state.

Eye/Nose Temperature. Emotions have been shown to induce physiological responses that include a shift in peripheral and internal temperatures. For instance, stressors, through the activation of the SNS, redirect peripheral blood to internal organs (i.e., the central nervous system and the muscles) via vasoconstriction of the peripheral arteries; the associated increase in deep body temperature is sometimes referred to as "stress-induced hyperthermia" (Zethof et al., 1994). This physiological mechanism is thought to support the fight-or-flight response by directing energy to internal organs. Infrared thermography offers a noninvasive way to measure subtle changes in peripheral body temperatures associated with the experience of different emotions. Research in humans has focused on changes in facial temperature, including specific regions of interest such as the mouth, cheeks, forehead, and eyes (Clay-Warner and Robinson, 2015), providing some basis to predict changes in peripheral body temperatures that can be used to assess emotional states.

In animals, studies have focused on the eyes in various species such as dogs (Travain et al., 2015, 2016), sheep (Stubsjøen et al., 2009), horses (Dai et al., 2015), and cattle (Stewart et al., 2008) and on other areas such as the comb in laying hens (Moe et al., 2012), and the tail in rodents (Vianna and Carrive, 2005; Lecorps et al., 2016).

In dairy cattle, eye temperature was found to quickly decrease (within the first minutes) after a painful procedure and then increase over baseline values for at least 15 to 20 min after the procedure (Stewart et al., $2008,2010)$. These authors were able to detect when the effect of a lidocaine nerve block waned around $2.5 \mathrm{~h}$ after hot-iron disbudding (Stewart et al., 2009). Thus, eye temperature changes might be a useful indicator of postoperative pain.

For such examples, it is difficult to disentangle the effects of fear and pain. In one study on castration, eye temperature decreased and then increased relative to baseline values in animals that were not given a nerve block, whereas animals given a nerve block showed an increase but no decrease in eye temperature (Stewart et al., 2010). These results could suggest that the initial drop in eye temperature, followed by an increase, is indicative of pain, whereas an increase only may be indicative of fear. Two recent studies found an increase in eye temperature when calves were handled and transported (Lecorps et al., 2018) or claw trimmed (Gómez 
et al., 2018), and other studies have reported increased temperature associated with fear-related situations in dogs (Travain et al., 2015), horses (Dai et al., 2015), mice (Lecorps et al., 2016), and humans (Levine et al., 2001).

The only cattle study that explored changes in eye temperature in positive situations found a slight increase during feeding (Gómez et al., 2018). Nasal temperature was found to decrease in both positive and negative situations (Proctor and Carder, 2015a, 2016). These authors used positive (receiving better feed than expected) and negative food-related contrasts (receiving unpalatable feed); further work is required to assess responses under more aversive situations. A study on laying hens also found decreased comb temperatures, during both fear conditioning and consumption of a reward (Moe et al., 2012).

Collectively, these results suggest that measures of peripheral temperature may provide a nonspecific indication of arousal. Many factors can affect temperature recordings, including camera settings, distance and angle between the camera and the region of interest, and environmental conditions such as ambient temperature, sunlight exposure, wind, and humidity (Church et al., 2014; Clay-Warner and Robinson, 2015), so acquisition and interpretation of these measures requires care.

Eye White. In humans, increased visible eye white (i.e., the percentage of eye white over the total area of the visible eye) has been used to assess emotional states including fear (Whalen et al., 2004; Fox and Damjanovic, 2006; Feng et al., 2009), but eye white has received little study in nonhuman animals. Work to date has focused primarily on sheep and cattle (Reefmann et al., 2009; Proctor and Carder, 2015b; Lambert (Proctor) and Carder, 2017). Increased eye white has been noted after cattle were exposed to the sudden opening of an umbrella (Sandem et al., 2004) and when heifers were milked for the first time without prior habituation to the milking parlor (Kutzer et al., 2015). Sandem and Braastad (2005) found that eye white also increased when cows were separated from their calves and that the magnitude of the response was correlated with other responses (including sniffing the ground where the calf had been, looking toward where the calf was taken, vocalizing, and pacing). In another example, hungry cows ( $7 \mathrm{~h}$ without feed) showed an increase in eye white when allowed to see their feed (through a plexiglass barrier) without being able to access it (Sandem et al., 2002). These cows also showed head shaking, tongue rolling, and vocal responses, none of which were observed in the cows that had full access to the feed.

Conversely, eye white was observed to decrease once dams were reunited with their calves (Sandem and
Braastad, 2005), when given access to feed after a period of restriction (Sandem et al., 2002) and during grooming (Proctor and Carder, 2015b). These results seem to indicate that increased eye white reflects negative affect and decreased eye white reflects positive affect, but other results undermine this idea. For example, eye white was observed to increase in cattle as much during undisturbed feeding as during restraint and claw trimming (Gómez et al., 2018). Increased eye white occurs in response to anticipation of feeding, thought to be a positive, high-arousal situation (Sandem et al., 2006). Making use of "feed" types thought to be positive (concentrate), neutral (standard ration), and negative (inedible woodchips), Lambert (Proctor) and Carder (2017) reported that both positive and negative stimuli resulted in increased eye white compared with the neutral feed. To our knowledge, this is the only study including stimuli varying in valence but focused on a similar event (feed provision) and thus, likely to be similar in arousal. Some authors have speculated that increased "eye openness" reflects increased attention to the environment (Sandem and Braastad, 2005). Increased attentiveness might be expected when animals are anxious but also when animals are anticipating positive outcomes, such as the opportunity to explore a novel environment or engage in social play. Thus, eye white appears to be another nonspecific indicator of affective arousal.

One advantage of eye white measures is the fast response time. For example, changes in eye white following transition between stroking and not stroking took less than $30 \mathrm{~s}$ (Proctor and Carder, 2015b). Similarly, increases in eye white due to food deprivation were apparent after 1 min (Sandem et al., 2002). One study found that eye white in cows remained higher than baseline for $5.5 \mathrm{~h}$ following separation from their calf (Sandem and Braastad, 2005), but otherwise there is little evidence to indicate that changes in eye white reflect longer-term events.

Based on the evidence reviewed above, we suggest that measures related to the activation of the HPA axis and the sympathetic and parasympathetic nervous systems mainly allow inferences about affective arousal, with less basis for inferences regarding whether affect is positive or negative, let alone the specific affective state experienced.

\section{Behavioral Responses}

Escape, Wound-Directed, and Evoked Behaviors. Pain is often assessed using behaviors expressed by animals during and following a painful condition but not expressed by control animals (Weary et al., 2006; Millman, 2013). Escape behaviors provide one obvious 
example. For instance, calves disbudded with a hotiron without local anesthesia rear and push (Stafford and Mellor, 2005a, 2011), calves surgically castrated struggle and kick (Fell et al., 1986), and steers branded exert more force on the head gate and squeeze chute compared with steers receiving a sham treatment (Schwartzkopf-Genswein et al., 1997b).

Although these behaviors are associated with nociceptive processes (i.e., the sensory detection of physical damage), they may be less useful for drawing inferences regarding the affective component of pain (Sneddon, 2018; Weary et al., 2017), just as our immediate withdrawal reflex from heat is not evidence of an affective pain response.

Wound-directed behaviors do allow inferences about the where of the affective experience, even if details about the what are less clear. For example, in the hours following hot-iron disbudding, calves show increased attention toward the injured area, including an increased frequency of ear flicks and head shakes (McMeekan et al., 1999; Sylvester et al., 2004; Winder et al., 2018). However, some variation in results might be explained by changes in behaviors less likely to be useful, such as changes in activity. For example, castration in lambs was associated with both decreased and increased physical activity depending on whether the surgical or rubber ring method was used (Mellor et al., 2000). More specific inferences about the where of pain may be possible in such cases if the specific anatomical structures involved in the movement are known. For example, an increased frequency of abdominal hunching (and decreased frequency of abdominal stretching) is expected in cases of injuries to abdominal muscles or inflammation of the visceral organs (Stojkov et al., 2015). In addition to these spontaneous responses, evoked behaviors (e.g., withdrawal in response to tissue stimulation) can also be used to make inferences about the where of pain. To draw stronger inferences about pain requires further interventions; for example, the use of appropriate analgesic treatments. Even in such cases, inferences regarding the affective component of pain will be limited, as some responses may simply reflect a nociceptive component of low intensity pain (as pointed out by Stafford and Mellord, 2005b, interest in the scrotal area following castration may indicate "extreme pain or minor irritation, or anything in between").

Vocalizations. As described by Watts and Stookey (2000), cattle vocalizations can be seen as a subjective commentary by an individual on its own internal state. The challenge then lies in understanding that commentary.

Vocalizations have been studied in contexts expected to be negative for cattle. For example, cows have been reported to vocalize when separated from their calves, and this response increases when cow and calf have been allowed to bond for several days (Flower and Weary, 2001; Stěhulová et al., 2008). Cattle also vocalize when food quantity is reduced (Schütz et al., 2013), as well as during and after painful procedures (Watts and Stookey, 1999; Caray et al., 2015).

However, the relationship between vocalizations and affect is far from straightforward. For example, increased calling is observed during estrus (Schön et al., 2007), where any link to affect is unclear. Increased vocalizations have also been observed in cows transitioned from tiestalls to freestalls (Pavlenko et al., 2018) and in calves during social play (Wagner et al., 2013), suggesting that a vocal response is not specific to negative events. Moreover, vocal responses are highly variable among individuals even in response to clearly negative events. For example, only 10 to $20 \%$ of cattle vocalize in response to castration (Stilwell et al., 2008), electric prodding (Grandin, 2001), and electroejaculation (do Amaral et al., 2017).

Of course not all vocalizations have the same biological function, and more specific inferences about the nature of the affective experience may be possible by classifying vocalizations (e.g., by their spectral components; Green et al., 2018). For example, high-frequency vocalizations have been reported in cattle during social isolation (Rushen et al., 1999), calf-dam separation (Padilla de la Torre et al., 2015; Johnsen et al., 2018), feed restriction (Thomas et al., 2001), and hot-iron branding (Watts and Stookey, 1999). Conversely, cows produce low-frequency calls when in contact with their calves (Padilla de la Torre et al., 2015) or when lying down in a cubicle while ruminating (Meen et al., 2015). These results are consistent with the idea that high-frequency calls relate to negative affect and lowfrequency calls relate to more positive states, but other studies have reported no difference in the maximum frequency of vocalizations produced during social interaction, sexual behavior, and behaviors such as fleeing (Meen et al., 2015). This lack of difference might be due to similar arousal levels (Green et al., 2018).

Although vocalizations vary widely among species (Green et al., 2018), some insights may be drawn from studies on different species. For example, in a study assessing affect in goats, the number of calls seemed to reflect arousal, whereas variability in pitch seemed more related to valence (Briefer et al., 2015). More variable frequencies of "rumbles" were observed in elephants subjected to a negative social context (Soltis et al., 2011). Research on this topic remains sparse in dairy cattle, and more studies are required to draw strong conclusions regarding arousal or valence in cattle.

Facial Expressions. Efforts to use facial expressions as proxies for affective states and animal welfare 
have been made (Descovich et al., 2017). Langford et al. (2010) were among the first to use facial expressions and to explore the existence of a "pain face" in mice, which has been replicated in other species (Holden et al., 2014; MacRae et al., 2018; McLennan, 2018). Interestingly, orbital tightening is one of the key facial action units found in the human "pain face" (Prkachin, 1992) and has been found in many species in response to pain, but has not yet been explored in cattle.

Work to date on dairy cattle has focused mostly on ear postures. Some authors suggested that ear posture could be used as valence indicator in cattle. For instance, one study found different ear postures expressed in response to a positive contrast (receiving a better food than expected) and a negative contrast situation (receiving unpalatable woodchips instead of food; Lambert and Carder, 2019). Both situations triggered arousal as shown by increased HR but different ear postures (positive: backward ear posture; negative: forward ear posture). However, backward ear postures have been found both when cows were in pain (Gleerup et al., 2015) and when stroked, which has been suggested to induce positive affective states of low arousal (Schmied et al., 2008; Proctor and Carder, 2014). Thus, more work on ear postures is required before strong inferences regarding affective valence can be drawn.

\section{LEARNED RESPONSES}

Researchers have used responses that are shaped by the test situation and the animal's awareness of the contingencies to ask animals 3 types of question: this or that, yes or no, and how much.

\section{This or That?}

By allowing animals to choose, preference tests provide an intuitively compelling measure of how animals rank the options provided to them. For example, Telezhenko et al. (2007) provided group-housed cows the choice between rubber and concrete standing surfaces and found that most chose to stand on the rubber surface; it seems likely that this preference was driven by increased comfort associated with standing on the softer rubber. Interestingly, the preference for rubber standing surfaces was less pronounced among lame cows, likely because these animals were less able to compete for access to the preferred rubber mats; for studies looking at lame cows' standing and bedding preferences while alone, see Jensen et al. (2015) and Bak et al. (2016). The social environment is one of several potential confounders in such studies; other factors such as age of the animal, time of day, and novelty of the procedure can all affect preferences (Fraser and Nicol, 2011).

In another study, researchers assessed preferences for 3 lying surfaces: sand, straw, and rubber mats (Manninen et al., 2002). Cows preferred straw in winter but showed no preference during summer, illustrating that preferences can vary over time and with environmental conditions. Indeed, for some types of preference test, there is an expectation that they vary with environmental conditions. For example, as researchers predicted, cows preferred a water sprinkler more during warmer weather (Chen et al., 2013).

Preference tests have been used to tackle many topics: which plants cows prefer to graze (Dwyer, 1961; Rutter et al., 2004; Horadagoda et al., 2009), which flavors they like best (Nombekela et al., 1994), how much they favor variety in their food (Meagher et al., 2017), and how to improve milking systems (Hopster et al., 1998; Prescott et al., 1998), freestalls (Tucker et al., 2004) and water troughs (Teixeira et al., 2006). Despite the popularity of preference tests, they have only limited value in drawing inferences related to affect. The results provide a rank assessment of valence (option A is better than B) but both options could be good or bad, and the results often provide little insight as to importance of the preferred choice to the animal.

\section{Yes or No?}

By definition, rewards can be considered what an animal approaches and punishments what an animal seeks to avoid (Brush, 1971; Rashotte, 1979). Approach and avoidance responses can thus provide insight into the affective valence associated with options provided to animals.

For example, cattle that were shouted at or shocked with an electric prod at the end of a race took more time and required more force from the handler to be walked down the race than cows receiving a neutral control treatment (a person standing still), suggesting (as expected) that the animals consider being shouted at or shocked as unpleasant (Pajor et al., 2000). Similarly, cows kept a greater flight distance from a handler who had previously slapped and yelled at them than from a neutral handler (Hötzel et al., 2005). Conversely, cows that were stroked by their handlers during milking displayed less avoidance than control cows when approached during feeding (Windschnurer et al., 2009). Approach and avoidance responses thus seem to reflect the affective state associated with positive and negative events.

Some approach/aversion findings have limitations similar to those of preference tests; for example, less 
avoidance can be interpreted only as "better" and not necessarily as "good." However, if cows not only display less avoidance but also actively seek out their handlers (Bertenshaw and Rowlinson, 2008; Schmied et al., 2008), this provides stronger evidence that the interaction is accompanied by positive affect.

Bringing cows into the hoof-trimming chute has been reported to require more forceful interactions (such as hitting the cows or twisting their tails) over time (Lindahl et al., 2016), indicating (1) that hoof trimming is aversive, and (2) that the animals learn to recognize cues associated with this event. This type of learned aversion can lead to a negative spiral, as increased baulking associated with the trimming leads to rough handling by staff, making the procedure even more aversive for the animal. One way to avoid this spiral is to use counter-conditioning, by training cows to associate the experience with an added reward. The most obvious example of this on dairy farms is providing a food reward to cows for entering the milking stall; even a small reward can elicit a marked increase in the cow's motivation to enter (Ceballos and Weary, 2002). This approach leads to the questions of how much reward is required to counterbalance various negative events? We turn to this issue in the following section.

\section{How Much?}

Animals can be asked how much they are willing to work to access something they are motivated to acquire, or how much they are willing to give up to avoid something aversive, by using experimental approaches that create economic contingencies (Kirkden and Pajor, 2006; Jensen and Pedersen, 2008).

Active motivation tests (assessing willingness to "work") can be illustrated through one of the most fundamental motivational relationships: hunger and food. As we would expect, cows that have been food-restricted for longer periods are more motivated to access food (e.g., by walking greater distances; Schütz et al., 2006). In another study, motivation to access fresh food was assessed following milking with the use of a push gate that was increasingly weighted (von Keyserlingk et al., 2017). All cows were willing to push around $20 \mathrm{~kg}$ to enter the area with the food, but as weight was added to the gate, fewer cows were willing to push it open to access the food. In the same experiment, the cows' motivation to access pasture was evaluated. The weight that cows were willing to push for fresh food was similar to that for pasture access (an average maximum weight of approximately $35 \mathrm{~kg}$ ), suggesting that fresh food and pasture access were judged as similarly positive. Using the same methodology, cows showed motivation to ac- cess fresh feed and a mechanical brush (McConnachie et al., 2018), and were willing to push a much greater weight to access either of these resources than to enter an empty pen that contained neither feed nor brush. Although motivation to access fresh feed and the brush were not examined in identical ways, cows were motivated for both. Future studies are needed to compare the motivations.

An advantage of the weighted gate is that the task is relatively intuitive for the animal, but one important limitation is that at higher weights, cows might not push open the gate simply because they are physically unable to do so, not because they lack the motivation. This type of limitation may create a ceiling effect, limiting the ability to distinguish among highly motivated options. Other types of operant tasks may be more suitable in such cases, such as panel presses. For example, Holm et al. (2002) used this approach to show that calves work more for full social contact with a peer than for head contact only. Webb et al. (2014) also used a panel-press design, this time integrating preference and motivational testing. Calves were trained to work for different types of forage from 2 simultaneously available feeders. Calves had to pay varying costs (i.e., number of presses) to access the different feeds, and the strength of preference was inferred by deviations from equality (i.e., not paying the same cost for both rewards).

Although motivation to work is used as evidence that the resource is viewed positively, work itself can also be a positive experience, perhaps especially in understimulating environments. This phenomenon, known as contrafreeloading, is demonstrated when animals work for a resource that is also freely available (Osborne, 1977; Van Os et al., 2018). Contrafreeloading could result in overestimating an animal's motivation to access the resource and illustrates the importance of including appropriate controls in these designs.

Another way to avoid this bias is to adopt a reversed approach and determine how much animals are willing to sacrifice. In a recent study, we trained dairy calves to approach a 1-L milk reward after $12 \mathrm{~h}$ of feed restriction. As expected, all calves were quick to approach the reward. These calves were then randomly assigned to 1 of 4 injection methods that they received upon reaching the milk (intramuscular, subcutaneous, intranasal, and a control group that was not injected). Initially, injected calves did not differ from the control group in latency to approach the reward. However, as the volume of milk reward decreased, injected groups took longer to reach the reward, especially when calves were injected intramuscularly (Ede et al., 2018). By giving up a resource that was highly valued, calves demonstrated 


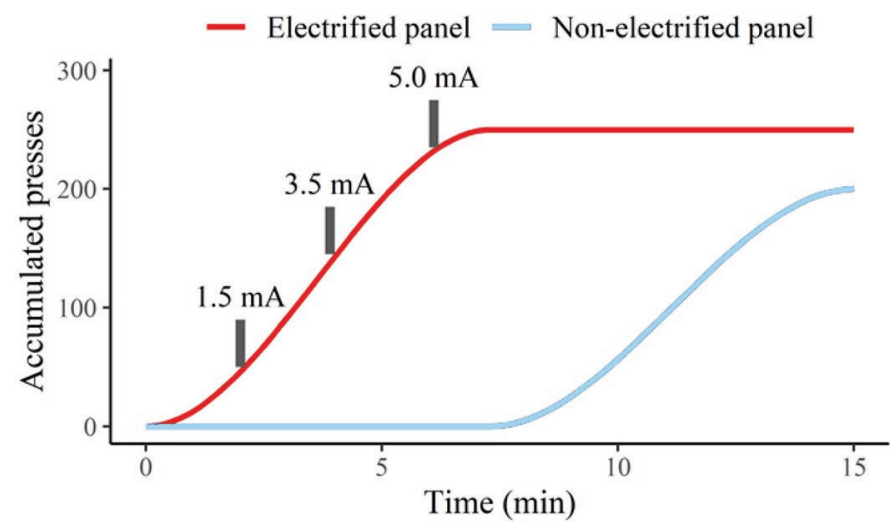

Figure 2. Results adapted from Whittlestone et al. (1975). Cows abandoned their interactions with a panel delivering food rewards when it was associated with electric shocks of increasing current. In this example, the threshold current at which the cow switched to the non-electrified panel was $5.0 \mathrm{~mA}$.

the price they were willing to pay to avoid injections, most likely in relation to the pain they associated with these injections.

Another example of this "giving up something valued" approach is an older study on stray voltage (Whittlestone et al., 1975). Cows were initially presented with 2 panels they could press, both with an equal probability of delivering a food reward (crushed barley). Then, one panel was switched off (i.e., it would not deliver rewards any more) until cows directed around $90 \%$ of their presses to the other, still active panel. Once this threshold was reached, presses to the active panel were associated with electric shocks of increasing current until the cows switched their presses back to the unrewarded (and unelectrified) panel (Figure 2). This design was used to pinpoint what electric shock was sufficiently negative that the food reward was abandoned.

A potential limitation of learning paradigms is the development of "learned helplessness," resulting in animals abandoning their attempts to avoid a negative event due to a perceived lack of control (Maier and Seligman, 1976); care is required to avoid confounding this phenomenon with the event being perceived as neutral.

In summary, addressing the this or that, yes or no, and how much questions provides insight into what animals judge as positive or negative and, in the latter case, how important obtaining or avoiding the stimulus is to the cow.

\section{MOOD ASSESSMENT}

Moods are considered persistent emotional states that result from the accumulation of positive and negative emotional experiences (Boissy and Lee, 2014). Mood states are increasingly viewed as important for animal welfare (Paul et al., 2005). Studies have attempted to assess changes in mood associated with housing conditions (Zidar et al., 2018), painful procedures (Neave et al., 2013), and chronic stress (Destrez et al., 2013) in farm animals. The majority of these studies have relied on cognitive approaches to assess these states.

\section{Cognitive Biases}

Cognitive bias refers to how emotions can affect cognitive processes such as attention, memory, and judgment (Paul et al., 2005). The literature provides a basis for making predictions about how affect, especially valence, induces positive or negative biases. We will explore how these methodologies have been used or could be used in cattle.

Attention. Attention bias refers to "the differential allocation of attention toward one stimulus compared with others" (Crump et al., 2018). Many studies have shown that humans and animals direct their attention to cues depending upon their affective state. Negative emotions trigger increased attention to negative information and potential threats, whereas positive emotions increase attention to positive information (Mathews and MacLeod, 1994; Crump et al., 2018). Different experimental designs have been used in animals (reviewed in Crump et al., 2018), but most aim at comparing the attention given to different cues, usually of positive or negative value, presented either separately or simultaneously. In this type of paradigm, measures of attention bias include what stimulus is looked at and for how long. One design used in farm animals focuses on attention to a threat (i.e., a dog) by cattle and sheep approaching a food reward. Both species were more attentive and slower to eat the reward when an anxiogenic drug was administered compared with controls (i.e., no anxiogenic; Lee et al., 2016, 2018), providing support for an affect-basis to these responses. In addition, Monk et al. (2018) suggest that attention bias tests can differentiate pharmacologically induced anxiety from depression, as depressed sheep increased attention toward the threat, whereas anxious sheep increased their attention toward a positive stimulus (i.e., a picture of a conspecific).

Attention biases do not require extensive training and can thus be applied relatively easily, especially compared with other cognitive bias tasks (Crump et al., 2018). However, some studies have failed to detect mood-induced differences. For example, a study on European starlings found no effect of the birds' emotional state (anxiety induced by threatening calls) on level of attention, perhaps because the negative stimulus 
was not sufficiently threatening (Brilot et al., 2009). Other studies have observed results that go in the opposite-to-expected direction. For example, Bethell et al. (2012) measured gaze in stressed versus nonstressed macaques and found that the stressed monkeys gazed for a shorter duration at the threatening stimulus. The stressed monkeys might have displayed avoidance because they perceived the negative stimulus as more threatening. Work on humans has also found increased and decreased attention to different threatening cues (Cisler and Koster, 2010).

Attention bias tasks share features with some paradigms used for personality testing in animals (i.e., startle, novel object, and unfamiliar human tests; Forkman et al., 2007). These tests rely on novelty, so responses are expected to change with repeated testing. How reliable attention bias tasks are over repeated testing is unexplored. Future research should use different designs (i.e., single vs. dual stimuli presentation and threat-directed attention) in different emotion-eliciting situations in dairy cattle. Previous research has reported that anxious cattle pay more attention to an immediate threat (i.e., a dog; Lee et al., 2018), but new research is needed to generalize this response to other negative affects.

Memory. Emotions and moods can affect memory retrieval and storage, phenomena generally referred to as mood-congruent biases in memory (Paul et al., 2005). Positive affect is expected to improve storage and recall of positive memories and negative affect to improve storage and recall of negative memories (Burman and Mendl, 2018). Few studies have used moodcongruent memory biases to assess affective states in any animals (for a recent example on rats, see Burman and Mendl, 2018) and, to our knowledge, no study has done so in farm animals.

Judgment. Most studies using cognitive bias have focused on how decisions are affected by emotional state (Mendl et al., 2009). Animals are initially trained to discriminate between a cue associated with a positive outcome and another cue associated with a negative or a less positive outcome. Once trained, animals are subjected to ambiguous cues intermediate relative to the training cues. Animals show stimulus generalization (i.e., show intermediate responses to the intermediate test cues), but in some cases the responses are more positive (or negative) than expected, suggesting that the animals are expecting a positive (or negative) outcome. A positive bias can be interpreted as optimistic and a negative bias as pessimistic. Many studies have shown a pessimistic response bias when animals were exposed to treatments expected to induce negative affect. For instance, work on dairy calves found a negative judgment bias in the hours following hot-iron disbudding (Neave et al., 2013; Daros et al., 2014) and separation from the dam (Daros et al., 2014). Work on other farm animals has explored the effects of different types of housing (pigs; Douglas et al., 2012), prenatal stress (lambs; Coulon et al., 2015) and chronic stress (sheep; Destrez et al., 2012). No study to date has examined judgment biases in adult dairy cattle.

Judgment bias tests allow for inferences regarding affective valence (Paul et al., 2005) but have several limitations (Roelofs et al., 2016). The most obvious of these is the need to train animals to discriminate between the training cues. In addition, an important premise of judgment bias tests is that test cues are ambiguous. However, with repeated testing, animals may learn to recognize these cues. For example, Barker et al. (2018) found decreased responsiveness to (unrewarded) ambiguous cues following repeated presentations. Different strategies have been used to mitigate this effect, including partial reinforcement of training cues (Neave et al., 2013) and reducing the number of ambiguous cues presented during testing (Hintze et al., 2018); these methods are likely to slow learning but not entirely inhibit it. Another limitation is that changes in response rate may reflect changes in how much animals value the reward rather than changes in their expectation of a reward; for example, feed motivation can vary with mood, as described in the next section. Finally, future studies should explore whether judgment bias tests are sensitive to moods of different intensity. An interesting approach would be to compare animals that receive different postoperative pain control medications after disbudding. We predict that animals with more efficient pain control would show lower judgment bias than control animals (receiving only a sedative and a local block). If true, this evidence would suggest that judgment biases can be used to draw inferences about valence and intensity of the mood change.

Anhedonia. Anhedonia, defined as a reduced ability to pursue and enjoy pleasurable activities (Treadway and Zald, 2011), is a sign of depression in humans that typically affects both wanting (motivation) and liking (pleasure). Propensity to forgo pleasurable activities has been explored in laboratory rodents, mainly assessed using the consumption of a sweet solution (Rizvi et al., 2016). Surprisingly little work has focused on anhedonia in farm animals. One exception is a study by Figueroa et al. (2015), showing that restraint and social stress decreased consumption of a sweet solution in pigs. No research to date has used this approach in cattle but a recent study showed that dairy calves reduce their interest in the positive cue (i.e., milk) in a judgment bias test $6 \mathrm{~h}$ after hot-iron disbudding (Lecorps et al., 2019), a result consistent with existing models of anhedonia. Other work on cattle has measured changes in other 
behaviors assumed to be pleasurable. For example, play behavior has been observed to decrease after hot-iron disbudding (Rushen and de Passillé, 2012; Mintline et al., 2013) and weaning (Rushen and de Passillé, 2012). Thus, measures of anhedonia seem to show some promise for assessing affective valence in dairy cattle.

\section{PHARMACOLOGICAL INTERVENTIONS}

Drugs with known effects on emotional states in humans can be used to study affective states of animals. In cattle, the inclusion of drugs has mostly focused on sedatives (e.g., xylazine), anesthetics (e.g., lidocaine), and analgesics (e.g., meloxicam, ketoprofen) in the study of painful procedures (Adcock and Tucker, 2018). These studies typically rely upon physiological and acute behavioral responses discussed above, and thus may be of limited value for drawing inferences about the felt component of affective states.

More sophisticated approaches allow for stronger inferences. For example, Van Reenen et al. (2009) reported that calves treated with the anxiolytic drug brotizolam spent more time near, and in contact with, a novel object than calves treated with saline, suggesting that interaction with a novel object is related to fear in calves. Another interesting approach is to allow animals to self-medicate; for example, lame chickens were found to prefer eating feed spiked with an analgesic (carprofen) than unspiked feed, whereas healthy chickens showed no preference (Danbury et al., 2000). We note that other authors have failed to replicate these results (Siegel et al., 2011). Following the same principle, mice housed in unpredictable conditions displayed a preference for water spiked with an antianxiety drug (midazolam), whereas mice housed in a predictable environment did not (Sherwin and Olsson, 2004). The strength of this approach is that it addresses the question of what (pain in the case of selection of analgesics; fear in the case of anxiolytics) and yes/no/how much (by assessing preference and sometimes motivation). Unfortunately, experiments demonstrating self-selection of drugs have not yet been reported in cattle. Given the strength of inferences allowed by this approach, it seems odd that so few studies have been published. We speculate that the dearth of studies is due to the difficulty in training animals to associate ingestion of a drug (typically delivered in feed or water) with the delayed effects of the drug, a delay likely accentuated because of the dilution of pharmaceutical agents in the large digestive tract of cattle. Yet, self-selection paradigms still show potential; work in cattle and other ruminants suggests that they are able to vary their dietary choices to self-medicate, for example, by increasing roughage intake after sub- acute ruminal acidosis induction (Keunen et al., 2002; but see also Paton et al., 2006).

Another experimental approach (known as "drug naming") relies upon animals comparing their current affective state with that induced by a drug. For example, rats were trained to press specific levers depending on whether they were treated with saline or an anxiogenic drug (pentylenetetrazole). Following exposure to a cat (also assumed to be anxiogenic), rats displayed the response associated with pentylenetetrazole (Gauvin and Holloway, 1991). To our knowledge, such a paradigm has not yet been explored in cattle.

\section{GENERAL DISCUSSION}

Spontaneous physiological and behavioral responses can be helpful in the study of affect but most measures are more reflective of arousal. This means that these measures may be useful in showing the intensity of an affective state (especially during acute events), but are less valuable when investigating whether something is experienced positively or negatively. In scenarios where the valence of an event is intuitive (e.g., dehorning without pain control), arousal responses might be sufficient, but researchers need to be aware of any ceiling effects and consider that high arousal states are unlikely to be maintained over long periods due to metabolic limits.

Preference tests, approach/aversion, and motivational tests allow for stronger inferences regarding affective valence, but these tests also have limitations. First, many of the tests rely on comparative judgments, which do not allow inferences on absolute valence (i.e., positive or negative), only the relative value (i.e., better or worse). Furthermore, any test requiring animals to perform a task (which includes mood assessments such as cognitive biases and anhedonia tests) may be difficult in bored, lethargic, ill, or postpartum individuals. More generally, tests involving activity should consider that an animal's ability to move might be compromised, especially after surgical procedures or drug use, potentially confounding results. On a more fundamental note, motivational paradigms provide a clear estimate of what animals want but this might not be identical to what animals like (Pool et al., 2016; Gygax, 2017).

Pharmacological interventions, such as self-selection and drug-naming paradigms, allow for inferences regarding specific affective states (e.g., anxiety vs. pain), rather than just valence. Again however, there are limitations. For instance, some drugs are initially aversive and then become appetitive (Tzschentke, 1998). Other drugs may have muscle-relaxing or memory-altering properties (Hall et al., 2001), making it difficult to draw inferences without the use of well-considered controls. 
Moreover, most drugs have not been validated in cattle and assumptions regarding efficacy across species require caution, especially when interpreting null results.

Paradigms based on learned responses rely on the animal's capacity to learn a connection between their behavior and an outcome, and thus also rely upon the researcher's ability to allow the animal to learn. Training typically requires some knowledge of the animal (e.g., regarding vision, smell, hearing, social structure, locomotion), and researchers need to reflect upon the suitability of training methods when faced with null results.

Among the methods presented, it can be difficult to decide which to choose when attempting to assess affect. We suggest that researchers refrain from including many measures in a single experiment as this practice increases the risk of false positives, weakening the reliability of conclusions. Rather, we encourage researchers to limit their focus to just one or a few measures with clearly stated predictions.

\section{CONCLUSIONS}

Within the valence/arousal framework, spontaneous behavioral and physiological responses more likely to reflect arousal than valence. Paradigms relying on learned responses such as preference tests, approach/ aversion, and motivation and mood assessments appear to be more valuable when assessing valence. The use of drugs with known effects on emotional states in humans can allow for inferences regarding specific affective states in animals.

\section{ACKNOWLEDGMENTS}

We thank the many members of the University of British Columbia Animal Welfare Program for their insights on this topic. Our group's work on affective states in cattle is primarily funded by a Discovery grant from Canada's Natural Science and Engineering Research Council to D.M.W. More generally, our work on cattle welfare is funded by an NSERC Industrial Research Chair with industry contributions from the Dairy Farmers of Canada (Ottawa, ON, Canada), British Columbia Dairy Association (Burnaby, BC, Canada), Westgen Endowment Fund (Milner, BC, Canada), Intervet Canada Corporation (Kirkland, QC, Canada), Novus International Inc. (Oakville, ON, Canada), Zoetis (Kirkland, QC, Canada), BC Cattle Industry Development Fund (Kamloops, BC, Canada), Alberta Milk (Edmonton, AB, Canada), Valacta (St. Anne-deBellevue, QC, Canada), and CanWest DHI (Guelph, ON, Canada).

\section{REFERENCES}

Adcock, S. J. J., and C. B. Tucker. 2018. Painful procedures: When and what should we be measuring in cattle? Pages 157-198 in Advances in Cattle Welfare. Woodhead Publishing/Elsevier, Amsterdam, the Netherlands. https://doi.org/10.1016/B978-0-08-100938 $-3.00008-5$.

Andrade, O., A. Orihuela, J. Solano, and C. S. Galina. 2001. Some effects of repeated handling and the use of a mask on stress responses in zebu cattle during restraint. Appl. Anim. Behav. Sci. 71:175-181. https://doi.org/10.1016/S0168-1591(00)00177-5.

Bak, A. S., M. S. Herskin, and M. B. Jensen. 2016. Effect of sand and rubber surface on the lying behavior of lame dairy cows in hospital pens. J. Dairy Sci. 99:2875-2883. https://doi.org/10.3168/jds.2015 $-9937$.

Barker, T. H., G. S. Howarth, and A. L. Whittaker. 2018. Increased latencies to respond in a judgment bias test are not associated with pessimistic biases in rats. Behav. Processes 146:64-66. https: //doi.org/10.1016/j.beproc.2017.11.016.

Barrett, L. F. 1998. Discrete emotions or dimensions? The role of valence focus and arousal focus. Cogn. Emotion 12:579-599. https:/ /doi.org/10.1080/026999398379574.

Berntson, G. G., J. T. Bigger, D. L. Eckberg, P. Grossman, P. G. Kaufmann, M. Malik, H. N. Nagaraja, S. W. Porges, J. P. Saul, P. H. Stone, and M. W. V. D. Molen. 1997. Heart rate variability: Origins, methods, and interpretive caveats. Psychophysiology 34:623-648. https://doi.org/10.1111/j.1469-8986.1997.tb02140.x.

Bertenshaw, C. E., and P. Rowlinson. 2008. Exploring heifers' perception of "positive" treatment through their motivation to pursue a retreated human. Anim. Welf. 17:313-319.

Bethell, E. J., A. Holmes, A. MacLarnon, and S. Semple. 2012. Evidence that emotion mediates social attention in rhesus macaques. PLoS One 7:e44387. https://doi.org/10.1371/journal.pone .0044387 .

Bianca, W. 1958. The relation between respiratory rate and heart rate in the calf subjected to severe heat stress. J. Agric. Sci. 51:321324. https://doi.org/10.1017/S0021859600035139.

Billman, G. E. 2011. Heart rate variability-A historical perspective. Front. Physiol. 2. https://doi.org/10.3389/fphys.2011.00086.

Billman, G. E. 2013. The $\mathrm{LF} / \mathrm{HF}$ ratio does not accurately measure cardiac sympatho-vagal balance. Front. Physiol. 4:26. https://doi .org/10.3389/fphys.2013.00026.

Boissy, A., and C. Lee. 2014. How assessing relationships between emotions and cognition can improve farm animal welfare. Rev. Sci. Tech. 33:103-110. https://doi.org/10.20506/rst.33.1.2260.

Boissy, A., G. Manteuffel, M. B. Jensen, R. O. Moe, B. Spruijt, L. J. Keeling, C. Winckler, B. Forkman, I. Dimitrov, J. Langbein, M. Bakken, I. Veissier, and A. Aubert. 2007. Assessment of positive emotions in animals to improve their welfare. Physiol. Behav. 92:375-397. https://doi.org/10.1016/j.physbeh.2007.02.003.

Bootsma, M., C. A. Swenne, H. H. Van Bolhuis, P. C. Chang, V. M. Cats, and A. V. Bruschke. 1994. Heart rate and heart rate variability as indexes of sympathovagal balance. Am. J. Physiol. 266:H1565-H1571. https://doi.org/10.1152/ajpheart.1994.266.4 .H1565.

Bradley, M. M., and P. J. Lang. 1994. Measuring emotion: The self-assessment manikin and the semantic differential. J. Behav. Ther. Exp. Psychiatry 25:49-59. https://doi.org/10.1016/0005 -7916(94)90063-9.

Briefer, E. F., F. Tettamanti, and A. G. McElligott. 2015. Emotions in goats: Mapping physiological, behavioural and vocal profiles. Anim. Behav. 99:131-143. https://doi.org/10.1016/j.anbehav.2014 .11 .002 .

Brilot, B. O., C. L. Normandale, A. Parkin, and M. Bateson. 2009. Can we use starlings' aversion to eyespots as the basis for a novel "cognitive bias" task? Appl. Anim. Behav. Sci. 118:182-190. https: //doi.org/10.1016/j.applanim.2009.02.015.

Broom, D. M. 1988. The scientific assessment of animal welfare. Appl. Anim. Behav. Sci. 20:5-19. https://doi.org/10.1016/0168 -1591(88)90122-0. 
Broom, D. M. 1991. Animal welfare: Concepts and measurement. J. Anim. Sci. 69:4167-4175. https://doi.org/10.2527/1991.69104167x.

Brosschot, J. F., E. Van Dijk, and J. F. Thayer. 2007. Daily worry is related to low heart rate variability during waking and the subsequent nocturnal sleep period. Int. J. Psychophysiol. 63:39-47. https://doi.org/10.1016/j.ijpsycho.2006.07.016.

Brush, F. R. 1971. Aversive Conditioning and Learning. Academic Press, London, UK. https://doi.org/10.1016/c2013-0-10435-7.

Burman, O. H. P., and M. T. Mendl. 2018. A novel task to assess mood congruent memory bias in non-human animals. J. Neurosci. Methods 308:269-275. https://doi.org/10.1016/j.jneumeth.2018.07.003.

Burnett, T. A., A. M. L. Madureira, B. F. Silper, A. Nadalin, A. Tahmasbi, D. M. Veira, and R. L. A. Cerri. 2014. Short communication: Factors affecting hair cortisol concentrations in lactating dairy cows. J. Dairy Sci. 97:7685-7690. https://doi.org/10.3168/ jds.2014-8444.

Camm, A. J., M. Malik, J. T. Bigger, G. Breithardt, S. Cerutti, R. J. Cohen, P. Coumel, E. L. Fallen, H. L. Kennedy, R. E. Kleiger, F. Lombardi, A. Malliani, A. J. Moss, J. N. Rottman, G. Schmidt, P. J. Schwartz, and D. H. Singer. 1996. Heart rate variability: Standards of measurement, physiological interpretation and clinical use. Task force of the European Society of Cardiology and the North American Society of Pacing and Electrophysiology. Circulation 93:1043-1065. https://doi.org/10.1161/01.CIR.93.5.1043.

Caray, D., A. de Boyer des Roches, S. Frouja, S. Andanson, and I. Veissier. 2015. Hot-iron disbudding: stress responses and behavior of 1- and 4-week-old calves receiving anti-inflammatory analgesia without or with sedation using xylazine. Livest. Sci. 179:22-28. https://doi.org/10.1016/j.livsci.2015.05.013.

Ceballos, A., and D. M. Weary. 2002. Feeding small quantities of grain in the parlour facilitates pre-milking handling of dairy cows: A note. Appl. Anim. Behav. Sci. 77:249-254. https://doi.org/10 .1016/S0168-1591(02)00054-0.

Chalmers, D. J. 1995. Facing up to the problem of consciousness. J. Conscious. Stud. 2:200-219. https://doi.org/10.1093/acprof:oso/ 9780195311105.003.0001.

Chen, J. M., K. E. Schütz, and C. B. Tucker. 2013. Dairy cows use and prefer feed bunks fitted with sprinklers. J. Dairy Sci. 96:50355045. https://doi.org/10.3168/jds.2012-6282.

Church, J. S., P. R. Hegadoren, M. J. Paetkau, C. C. Miller, G. RegevShoshani, A. L. Schaefer, and K. S. Schwartzkopf-Genswein. 2014. Influence of environmental factors on infrared eye temperature measurements in cattle. Res. Vet. Sci. 96:220-226. https://doi.org/ 10.1016/j.rvsc.2013.11.006.

Cisler, J. M., and E. H. W. Koster. 2010. Mechanisms of attentional biases towards threat in anxiety disorders: An integrative review. Clin. Psychol. Rev. 30:203-216. https://doi.org/10.1016/j.cpr.2009 .11 .003 .

Clapp, J. B., S. Croarkin, C. Dolphin, and S. K. Lyons. 2015. Heart rate variability: A biomarker of dairy calf welfare. Anim. Prod. Sci. 55:1289-1294. https://doi.org/10.1071/AN14093.

Clay-Warner, J., and D. T. Robinson. 2015. Infrared thermography as a measure of emotion response. Emot. Rev. 7:157-162. https://doi .org $/ 10.1177 / 1754073914554783$.

Coetzee, J. F., B. V. Lubbers, S. E. Toerber, R. Gehring, D. U. Thomson, B. J. White, and M. D. Apley. 2008. Plasma concentrations of substance $\mathrm{P}$ and cortisol in beef calves after castration or simulated castration. Am. J. Vet. Res. 69:751-762. https://doi.org/10 $.2460 /$ ajvr.69.6.751.

Colborn, D. R., D. L. Thompson, T. L. Roth, J. S. Capehart, and K. L. White. 1991. Responses of cortisol and prolactin to sexual excitement and stress in stallions and geldings. J. Anim. Sci. 69:2556. https://doi.org/10.2527/1991.6962556x.

Coulon, M., R. Nowak, S. Andanson, B. Petit, F. Lévy, and A. Boissy. 2015. Effects of prenatal stress and emotional reactivity of the mother on emotional and cognitive abilities in lambs. Dev. Psychobiol. 57:626-636. https://doi.org/10.1002/dev.21320.

Crump, A., G. Arnott, E. Bethell, A. Crump, G. Arnott, and E. J. Bethell. 2018. Affect-driven attention biases as animal welfare indicators: Review and methods. Animals (Basel) 8:136. https://doi .org/10.3390/ani8080136.
Dai, F., N. H. Cogi, E. U. L. Heinzl, E. Dalla Costa, E. Canali, and M. Minero. 2015. Validation of a fear test in sport horses using infrared thermography. J. Vet. Behav. 10:128-136. https://doi.org/10 $.1016 /$ j.jveb.2014.12.001.

Danbury, T. C., C. A. Weeks, J. P. Chambers, A. E. Waterman-Pearson, and S. C. Kestin. 2000. Self-selection of the analgesic drug carprofen by lame broiler chickens. Vet. Rec. 146:307-311. https:/ /doi.org/10.1136/vr.146.11.307.

Daros, R. R., J. H. C. Costa, M. A. G. von Keyserlingk, M. J. Hötzel, and D. M. Weary. 2014. Separation from the dam causes negative judgement bias in dairy calves. PLoS One 9:e98429. https://doi .org/10.1371/journal.pone.0098429.

Descovich, K. A., J. Wathan, M. C. Leach, H. M. Buchanan-Smith, P. Flecknell, D. Farningham, and S. J. Vick. 2017. Facial expression : An under-utilised tool for the assessment of welfare in mammals. ALTEX 34:409-429. https://doi.org/10.14573/altex.1607161.

Destrez, A., V. Deiss, C. Belzung, C. Lee, and A. Boissy. 2012. Does reduction of fearfulness tend to reduce pessimistic-like judgment in lambs? Appl. Anim. Behav. Sci. 139:233-241. https://doi.org/ 10.1016/j.applanim.2012.04.006.

Destrez, A., V. Deiss, F. Lévy, L. Calandreau, C. Lee, E. ChaillouSagon, and A. Boissy. 2013. Chronic stress induces pessimistic-like judgment and learning deficits in sheep. Appl. Anim. Behav. Sci. 148:28-36. https://doi.org/10.1016/j.applanim.2013.07.016.

do Amaral, J. B., R. M. L. Pires, L. A. Ambrósio, F. A. de Oliveira, and G. Trevisan. 2017. Facial expression, vocalization and abnormal postures of cattle submitted to conventional electroejaculation. Pubvet 11:1085-1097.

Douglas, C., M. Bateson, C. Walsh, A. Bédué, and S. A. Edwards. 2012. Environmental enrichment induces optimistic cognitive biases in pigs. Appl. Anim. Behav. Sci. 139:65-73. https://doi.org/ 10.1016/j.applanim.2012.02.018.

Dwyer, D. D. 1961. Activities and grazing preferences of cows with calves in Northern Osage County, Oklahoma. Bull. Okla. Agric. Exp. Stn. B-588:61. Oklahoma State University, Stillwater.

Ede, T., M. A. G. von Keyserlingk, and D. M. Weary. 2018. Approachaversion in calves following injections. Sci. Rep. 8:9443. https://doi .org/10.1038/s41598-018-27669-7.

Fell, L. R., R. Wells, and D. A. Shutt. 1986. Stress in calves castrated surgically or by the application of rubber rings. Aust. Vet. J. 63:16-18. https://doi.org/10.1111/j.1751-0813.1986.tb02864.x.

Feng, W., W. Luo, Y. Liao, N. Wang, T. Gan, and Y. Luo. 2009. Human brain responsivity to different intensities of masked fearful eye whites: An ERP study. Brain Res. 1286:147-154. https://doi .org/10.1016/j.brainres.2009.06.059.

Figueroa, J., D. Solà-Oriol, X. Manteca, J. F. Pérez, and D. M. Dwyer. 2015. Anhedonia in pigs? Effects of social stress and restraint stress on sucrose preference. Physiol. Behav. 151:509-515. https:// doi.org/10.1016/j.physbeh.2015.08.027.

Fisher, A. D., M. A. Crowe, M. E. Alonso de la Varga, and W. J. Enright. 1996. Effect of castration method and the provision of local anesthesia on plasma cortisol, scrotal circumference, growth, and feed intake of bull calves. J. Anim. Sci. 74:2336. https://doi.org/ $10.2527 / 1996.74102336 \mathrm{x}$.

Flower, F. C., and D. M. Weary. 2001. Effects of early separation on the dairy cow and calf: 2 . Separation at 1 day and 2 weeks after birth. Appl. Anim. Behav. Sci. 70:275-284. https://doi.org/10 .1016/S0168-1591(00)00164-7.

Forkman, B., A. Boissy, M.-C. Meunier-Salaün, E. Canali, and R. B. Jones. 2007. A critical review of fear tests used on cattle, pigs, sheep, poultry and horses. Physiol. Behav. 92:340-374. https://doi .org/10.1016/j.physbeh.2007.03.016.

Fox, E., and L. Damjanovic. 2006. The eyes are sufficient to produce a threat superiority effect. Emotion 6:534-539. https://doi.org/10 .1037/1528-3542.6.3.534.

Fraser, D. 2008. Understanding animal welfare. Acta Vet. Scand. 50:S1. https://doi.org/10.1186/1751-0147-50-S1-S1.

Fraser, D., and I. Duncan. 1998. "Pleasures", "pains" and animal welfare: Toward a natural history of affect. Anim. Welf. 7:383-396. https://doi.org/10.1093/oso/9780190225100.003.0008. 
Fraser, D., and C. J. Nicol. 2011. Preference and Motivation Research. 2nd ed. M. C. Appleby, J. A. Mench, I. A. S. Olsson, and B. O. Hughes, ed. CABI, Wallingford, UK. https://doi.org/10.1079/ 9781845936594.0183

Fraser, D., D. Weary, E. Pajor, and B. Milligan. 1997. A scientific conception of animal welfare that reflects ethical concerns. Anim. Welf. 6:187-205.

Gauvin, D. V., and F. A. Holloway. 1991. Cross-generalization between an ecologically relevant stimulus and a pentylenetetrazole-discriminative cue. Pharmacol. Biochem. Behav. 39:521-523. https://doi .org/10.1016/0091-3057(91)90220-v.

Geisler, F. C. M., N. Vennewald, T. Kubiak, and H. Weber. 2010. The impact of heart rate variability on subjective well-being is mediated by emotion regulation. Pers. Individ. Dif. 49:723-728. https:/ /doi.org/10.1016/j.paid.2010.06.015.

Giese, H., M. Dilly, Y. Gundelach, G. Hoffmann, and M. Schmicke. 2018. Influence of transrectal palpation training on cortisol levels and heart rate variability in cows. Theriogenology 119:238-244. https://doi.org/10.1016/j.theriogenology.2018.07.016.

Gleerup, K. B., P. H. Andersen, L. Munksgaard, and B. Forkman. 2015. Pain evaluation in dairy cattle. Appl. Anim. Behav. Sci. 171:25-32. https://doi.org/10.1016/j.applanim.2015.08.023.

Gómez, Y., R. Bieler, A. K. Hankele, M. Zähner, P. Savary, and E. Hillmann. 2018. Evaluation of visible eye white and maximum eye temperature as non-invasive indicators of stress in dairy cows. Appl. Anim. Behav. Sci. 198:1-8. https://doi.org/10.1016/j applanim.2017.10.001.

González, L. A., K. S. Schwartzkopf-Genswein, N. A. Caulkett, E. Janzen, T. A. McAllister, E. Fierheller, A. L. Schaefer, D. B. Haley, J. M. Stookey, and S. Hendrick. 2010. Pain mitigation after band castration of beef calves and its effects on performance, behavior, Escherichia coli, and salivary cortisol. J. Anim. Sci. 88:802-810.

Gorman, J. M., and R. P. Sloan. 2000. Heart rate variability in depressive and anxiety disorders. Am. Heart J. 140(4 Suppl.):77-83. https://doi.org/10.1067/mhj.2000.109981.

Graf, G. C., and W. E. Petersen. 1953. Changes in respiration and heart rates, body temperatures, plasma lactic acid levels and plasma creatinine levels caused by stress in dairy cattle. J. Dairy Sci. 36:1036-1048

Grandin, T. 2001. Cattle vocalizations are associated with handling and equipment problems at beef slaughter plants. Appl. Anim. Behav. Sci. 71:191-201. https://doi.org/10.1016/S0168-1591(00)00179-9.

Green, A. C., I. N. Johnston, and C. E. F. Clark. 2018. Invited review: The evolution of cattle bioacoustics and application for advanced dairy systems. Animal 12:1250-1259. https://doi.org/10.1017/ S1751731117002646.

Gygax, L. 2017. Wanting, liking and welfare: The role of affective states in proximate control of behaviour in vertebrates. Ethology 123:689-704. https://doi.org/10.1111/eth.12655.

Hagen, K., J. Langbein, C. Schmied, D. Lexer, and S. Waiblinger. 2005. Heart rate variability in dairy cows - influences of breed and milking system. Physiol. Behav. 85:195-204. https://doi.org/10 1016/j.physbeh.2005.03.019.

Hall, J. E., T. D. Uhrich, and T. J. Ebert. 2001. Sedative, analgesic and cognitive effects of clonidine infusions in humans. Br. J. Anaesth. 86:5-11. https://doi.org/10.1093/bja/86.1.5.

Hintze, S., L. Melotti, S. Colosio, J. D. Bailoo, M. Boada-Saña, H Würbel, and E. Murphy. 2018. A cross-species judgement bias task: Integrating active trial initiation into a spatial Go/No-go task. Sci. Rep. 8:5104. https://doi.org/10.1038/s41598-018-23459-3.

Holden, E., G. Calvo, M. Collins, A. Bell, J. Reid, E. M. Scott, and A. M. Nolan. 2014. Evaluation of facial expression in acute pain in cats. J. Small Anim. Pract. 55:615-621. https://doi.org/10.1111/ jsap. 12283

Holm, L., M. B. Jensen, and L. L. Jeppesen. 2002. Calves' motivation for access to two different types of social contact measured by operant conditioning. Appl. Anim. Behav. Sci. 79:175-194. https:/ /doi.org/10.1016/S0168-1591(02)00137-5.

Hopster, H., R. M. Bruckmaier, J. T. N. Van der Werf, S. M. Korte, J. Macuhova, G. Korte-Bouws, and C. G. van Reenen. 2002. Stress responses during milking; comparing conventional and automatic milking in primiparous dairy cows. J. Dairy Sci. 85:3206-3216. https://doi.org/10.3168/jds.S0022-0302(02)74409-3.

Hopster, H., J. T. N. van der Werf, and H. J. Blokhuis. 1998. Side preference of dairy cows in the milking parlour and its effects on behaviour and heart rate during milking. Appl. Anim. Behav. Sci. 55:213-229. https://doi.org/10.1016/S0168-1591(97)00064-6.

Horadagoda, A., W. J. Fulkerson, K. S. Nandra, and I. M. Barchia. 2009. Grazing preferences by dairy cows for 14 forage species. Anim. Prod. Sci. 49:586-594. https://doi.org/10.1071/EA08299.

Hötzel, M. J., L. C. P. Machado Filho, M. C. Yunes, and M. C. A. C. da Silveira. 2005. An aversive milker causes fear, but does not influence milk yield of Holstein cows. Rev. Bras. Zootec. 34:1278 1284. https://doi.org/10.1590/S1516-35982005000400024.

Jensen, M. B., M. S. Herskin, P. T. Thomsen, B. Forkman, and H. Houe. 2015. Preferences of lame cows for type of surface and level of social contact in hospital pens. J. Dairy Sci. 98:4552-4559. https://doi.org/10.3168/jds.2014-9203.

Jensen, M. B., and L. J. Pedersen. 2008. Using motivation tests to assess ethological needs and preferences. Appl. Anim. Behav. Sci 113:340-356. https://doi.org/10.1016/j.applanim.2008.02.001.

Jensen, P., and F. M. Toates. 1997. Stress as a state of motivational systems. Appl. Anim. Behav. Sci. 53:145-156. https://doi.org/10 .1016/s0168-1591(96)01156-2

Johnsen, J. F., C. M. Mejdell, A. Beaver, A. M. de Passillé, J. Rushen, and D. M. Weary. 2018. Behavioural responses to cow-calf separation: The effect of nutritional dependence. Appl. Anim. Behav. Sci. 201:1-6. https://doi.org/10.1016/j.applanim.2017.12.009.

Kazmi, S. Z. H., H. Zhang, W. Aziz, O. Monfredi, S. A. Abbas, S. A. Shah, S. S. H. Kazmi, and W. H. Butt. 2016. Inverse correlation between heart rate variability and heart rate demonstrated by linear and nonlinear analysis. PLoS One 11:e0157557. https://doi .org/10.1371/journal.pone.0157557.

Keunen, J. E., J. C. Plaizier, L. Kyriazakis, T. F. Duffield, T. M. Widowski, M. I. Lindinger, and B. W. McBride. 2002. Effects of a subacute ruminal acidosis model on the diet selection of dairy cows. J. Dairy Sci. 85:3304-3313. https://doi.org/10.3168/jds .S0022-0302(02)74419-6.

Kirkden, R. D., and E. A. Pajor. 2006. Using preference, motivation and aversion tests to ask scientific questions about animals' feelings. Appl. Anim. Behav. Sci. 100:29-47. https://doi.org/10.1016/ j.applanim.2006.04.009.

Kovács, L., V. Jurkovich, M. Bakony, O. Szenci, P. Póti, and J. Tőzsér. 2014. Welfare implication of measuring heart rate and heart rate variability in dairy cattle: Literature review and conclusions for future research. Animal 8:316-330. https://doi.org/10.1017/ S1751731113002140.

Kovács, L., F. L. Kézér, V. Jurkovich, M. Kulcsár-Huszenicza, and J. Tözsér. 2015. Heart rate variability as an indicator of chronic stress caused by lameness in dairy cows. PLoS One 10:e0134792. https://doi.org/10.1371/journal.pone.0134792.

Kreibig, S. D. 2010. Autonomic nervous system activity in emotion: A review. Biol. Psychol. 84:394-421. https://doi.org/10.1016/j .biopsycho.2010.03.010.

Kristal-Boneh, E., M. Raifel, P. Froom, and J. Ribak. 1995. Heart rate variability in health and disease. Scand. J. Work Environ. Health 21:85-95.

Kutzer, T., M. Steilen, L. Gygax, and B. Wechsler. 2015. Habituation of dairy heifers to milking routine - Effects on human avoidance distance, behavior, and cardiac activity during milking. J. Dairy Sci. 98:5241-5251. https://doi.org/10.3168/jds.2014-8773.

Lambert (Proctor), H. S., and G. Carder. 2017. Looking into the eyes of a cow: Can eye whites be used as a measure of emotional state? Appl. Anim. Behav. Sci. 186:1-6. https://doi.org/10.1016/j .applanim.2016.11.005.

Lambert, H., and G. Carder. 2019. Positive and negative emotions in dairy cows: Can ear postures be used as a measure? Behav. Processes 158:172-180. https://doi.org/10.1016/j.beproc.2018.12.007.

Langewitz, W., and H. Rüddel. 1989. Spectral analysis of heart rate variability under mental stress. J. Hypertens. Suppl. 7:S32-S33.

Langford, D. J., A. L. Bailey, M. L. Chanda, S. E. Clarke, T. E. Drummond, S. Echols, S. Glick, J. Ingrao, T. Klassen-Ross, M. L. 
LaCroix-Fralish, L. Matsumiya, R. E. Sorge, S. G. Sotocinal, J. M. Tabaka, D. Wong, A. M. J. M. van den Maagdenberg, M. D. Ferrari, K. D. Craig, and J. S. Mogil. 2010. Coding of facial expressions of pain in the laboratory mouse. Nat. Methods 7:447-449. https://doi.org/10.1038/nmeth.1455.

Lazarus, R. S., J. C. Speisman, and A. M. Mordkoff. 1963. The relationship between autonomic indicators of psychological stress: Heart rate and skin conductance. Psychosom. Med. 25:19-30. https://doi.org/10.1097/00006842-196301000-00004.

Lecorps, B., S. Kappel, D. M. Weary, and M. A. G. von Keyserlingk. 2018. Dairy calves' personality traits predict social proximity and response to an emotional challenge. Sci. Rep. 8:16350. https://doi .org/10.1038/s41598-018-34281-2.

Lecorps, B., B. R. Ludwig, M. A. G. von Keyserlingk, and D. M. Weary. 2019. Pain-induced pessimism and anhedonia: Evidence from a novel probability-based judgment bias test. Front. Behav. Neurosci. 13. https://doi.org/10.3389/fnbeh.2019.00054.

Lecorps, B., H. G. Rödel, and C. Féron. 2016. Assessment of anxiety in open field and elevated plus maze using infrared thermography. Physiol. Behav. 157:209-216. https://doi.org/10.1016/j.physbeh .2016.02.014

Lee, C., L. M. Cafe, S. L. Robinson, R. E. Doyle, J. M. Lea, A. H. Small, and I. G. Colditz. 2018. Anxiety influences attention bias but not flight speed and crush score in beef cattle. Appl. Anim. Behav. Sci. 205:210-215. https://doi.org/10.1016/j.applanim.2017 .11 .003 .

Lee, C., E. Verbeek, R. Doyle, and M. Bateson. 2016. Attention bias to threat indicates anxiety differences in sheep. Biol. Lett. 12:20150977. https://doi.org/10.1098/rsbl.2015.0977.

Levine, J. A., I. Pavlidis, and M. Cooper. 2001. The face of fear. Lancet 357:1757. https://doi.org/10.1016/S0140-6736(00)04936-9.

Lindahl, C., S. Pinzke, A. Herlin, and L. J. Keeling. 2016. Humananimal interactions and safety during dairy cattle handling-Comparing moving cows to milking and hoof trimming. J. Dairy Sci. 99:2131-2141. https://doi.org/10.3168/jds.2014-9210.

MacRae, A. M., I. Joanna Makowska, and D. Fraser. 2018. Initial evaluation of facial expressions and behaviours of harbour seal pups (Phoca vitulina) in response to tagging and microchipping. Appl. Anim. Behav. Sci. 205:167-174. https://doi.org/10.1016/j applanim.2018.05.001.

Maier, S. F., and M. E. Seligman. 1976. Learned helplessness: Theory and evidence. J. Exp. Psychol. Gen. 105:3-46. https://doi.org/10 .1037/0096-3445.105.1.3.

Manninen, E., A. M. de Passillé, J. Rushen, M. Norring, and H. Saloniemi. 2002. Preferences of dairy cows kept in unheated buildings for different kind of cubicle flooring. Appl. Anim. Behav. Sci. 75:281-292. https://doi.org/10.1016/S0168-1591(01)00206-4.

Mathews, A., and C. MacLeod. 1994. Cognitive approaches to emotion and emotional disorders. Annu. Rev. Psychol. 45:25-50. https:// doi.org/10.1146/annurev.ps.45.020194.000325.

McConnachie, E., A. M. C. Smid, A. J. Thompson, D. M. Weary, M. A. Gaworski, and M. A. G. von Keyserlingk. 2018. Cows are highly motivated to access a grooming substrate. Biol. Lett. 14:20180303. https://doi.org/10.1098/rsbl.2018.0303.

McLennan, K. 2018. Why pain is still a welfare issue for farm animals, and how facial expression could be the answer. Agriculture 8:127. https://doi.org/10.3390/agriculture8080127.

McMeekan, C., K. J. Stafford, D. J. Mellor, R. A. Bruce, R. N. Ward, and N. Gregory. 1999. Effects of a local anaesthetic and a nonsteroidal anti-inflammatory analgesic on the behavioural responses of calves to dehorning. N. Z. Vet. J. 47:92-96. https://doi.org/10 $.1080 / 00480169.1999 .36120$.

Meagher, R. K., D. M. Weary, and M. A. G. von Keyserlingk. 2017. Some like it varied: Individual differences in preference for feed variety in dairy heifers. Appl. Anim. Behav. Sci. 195:8-14. https:/ /doi.org/10.1016/j.applanim.2017.06.006.

Meen, G. H., M. A. Schellekens, M. H. M. Slegers, N. L. G. Leenders, E. van Erp-van der Kooij, and L. P. J. J. Noldus. 2015. Sound analysis in dairy cattle vocalisation as a potential welfare monitor. Comput. Electron. Agric. 118:111-115. https://doi.org/10.1016/j .compag.2015.08.028.
Mellor, D. J., C. J. Cook, and K. J. Stafford. 2000. Quantifying some responses to pain as a stressor. Pages 171-198 in The Biology of Animal Stress: Basic Principles and Implications for Animal Welfare. G. P. Moberg and J. A. Mench, ed. CABI, Wallingford, UK.

Mellor, D. J., and K. J. Stafford. 2000. Acute castration and/or tailing distress and its alleviation in lambs. N. Z. Vet. J. 48:33-43. https: //doi.org/10.1080/00480169.2000.36156.

Mendl, M., O. H. P. Burman, R. M. A. Parker, and E. S. Paul. 2009. Cognitive bias as an indicator of animal emotion and welfare: Emerging evidence and underlying mechanisms. Appl. Anim. Behav. Sci. 118:161-181. https://doi.org/10.1016/j.applanim.2009.02 .023 .

Mendl, M., O. H. P. Burman, and E. S. Paul. 2010. An integrative and functional framework for the study of animal emotion and mood. Proc. Biol. Sci. 277:2895-2904. https://doi.org/10.1098/rspb.2010 .0303 .

Meston, C. M. 2000. Sympathetic nervous system activity and female sexual arousal. Am. J. Cardiol. 86:30F-34F. https://doi.org/10 $.1016 / \mathrm{s} 0002-9149(00) 00889-4$

Millman, S. T. 2013. Behavioral responses of cattle to pain and implications for diagnosis, management, and animal welfare. Vet. Clin. North Am. Food Anim. Pract. 29:47-58. https://doi.org/10.1016/ j.cvfa.2012.11.007.

Mintline, E. M., M. Stewart, A. R. Rogers, N. R. Cox, G. A. Verkerk, J. M. Stookey, J. R. Webster, and C. B. Tucker. 2013. Play behavior as an indicator of animal welfare: Disbudding in dairy calves. Appl. Anim. Behav. Sci. 144:22-30. https://doi.org/10.1016/j .applanim.2012.12.008.

Moe, R. O., S. M. Stubsjøen, J. Bohlin, A. Flø, and M. Bakken. 2012 Peripheral temperature drop in response to anticipation and consumption of a signaled palatable reward in laying hens (Gallus domesticus). Physiol. Behav. 106:527-533. https://doi.org/10.1016/j .physbeh.2012.03.032.

Monfredi, O., A. E. Lyashkov, A.-B. Johnsen, S. Inada, H. Schneider, R. Wang, M. Nirmalan, U. Wisloff, V. A. Maltsev, E. G. Lakatta, H. Zhang, and M. R. Boyett. 2014. Biophysical characterisation of the under-appreciated and important relationship between heart rate variability and heart rate. Hypertension 64:1334-1343. https: //doi.org/10.1161/HYPERTENSIONAHA.114.03782.

Monk, J. E., S. Belson, I. G. Colditz, and C. Lee. 2018. Attention bias test differentiates anxiety and depression in sheep. Front. Behav. Neurosci. 12. https://doi.org/10.3389/fnbeh.2018.00246.

Montebugnoli, L., D. Servidio, R. A. Miaton, and C. Prati. 2004 Heart rate variability: A sensitive parameter for detecting abnormal cardiocirculatory changes during a stressful dental procedure. J. Am. Dent. Assoc. 135:1718-1723. https://doi.org/10.14219/ jada.archive.2004.0125

Müller, M. S., A. L. Vyssotski, M. Yamamoto, and K. Yoda. 2017. Heart rate variability reveals that a decrease in parasympathetic ("rest-and-digest") activity dominates autonomic stress responses in a free-living seabird. Comp. Biochem. Physiol. A Mol. Integr. Physiol. 212:117-126. https://doi.org/10.1016/j.cbpa.2017.07.007.

Neave, H. W., R. R. Daros, J. H. C. Costa, M. A. G. von Keyserlingk, and D. M. Weary. 2013. Pain and pessimism: Dairy calves exhibit negative judgement bias following hot-iron disbudding. PLoS One 8:e80556. https://doi.org/10.1371/journal.pone.0080556.

Nombekela, S. W., M. R. Murphy, H. W. Gonyou, and J. I. Marden. 1994. Dietary preferences in early lactation cows as affected by primary tastes and some common feed flavors. J. Dairy Sci. 77:23932399. https://doi.org/10.3168/jds.S0022-0302(94)77182-4.

Osborne, S. R. 1977. The free food (contrafreeloading) phenomenon: A review and analysis. Anim. Learn. Behav. 5:221-235. https://doi .org/10.3758/bf03209232.

Padilla de la Torre, M., E. F. Briefer, T. Reader, and A. G. McElligott. 2015. Acoustic analysis of cattle (Bos taurus) mother-offspring contact calls from a source-filter theory perspective. Appl. Anim. Behav. Sci. 163:58-68. https://doi.org/10.1016/j.applanim.2014.11 .017 .

Pajor, E. A., J. Rushen, and A. M. B. De Passillé. 2000. Aversion learning techniques to evaluate dairy cattle handling practices. 
Appl. Anim. Behav. Sci. 69:89-102. https://doi.org/10.1016/s0168 -1591(00)00119-2.

Palme, R., C. Robia, W. Baumgartner, and E. Mostl. 2000. Transport stress in cattle as reflected by an increase in faecal cortisol metabolite concentrations. Vet. Rec. 146:108-109. https://doi.org/10 $.1136 / v r .146 .4 .108$

Panksepp, J. 2005. Affective consciousness: Core emotional feelings in animals and humans. Conscious. Cogn. 14:30-80. https://doi.org/ 10.1016/j.concog.2004.10.004.

Parati, G., G. Mancia, M. D. Rienzo, and P. Castiglioni. 2006. Point: Counterpoint: Cardiovascular variability is/is not an index of autonomic control of circulation. J. Appl. Physiol. 101:676-678. https://doi.org/10.1152/japplphysiol.00446.2006.

Paton, L. J., K. A. Beauchemin, D. M. Veira, and M. A. von Keyserlingk. 2006. Use of sodium bicarbonate, offered free choice or blended into the ration, to reduce the risk of ruminal acidosis in cattle. Can. J. Anim. Sci. 86:429-437.

Paul, E. S., E. J. Harding, and M. Mendl. 2005. Measuring emotional processes in animals: The utility of a cognitive approach. Neurosci. Biobehav. Rev. 29:469-491. https://doi.org/10.1016/j.neubiorev .2005.01.002

Pavlenko, A., L. Lidfors, D. R. Arney, T. Kaart, and A. Aland. 2018 Behavior and performance of dairy cows after transfer from tied to cubicle housing. J. Appl. Anim. Welf. Sci. 21:82-92. https://doi .org/10.1080/10888705.2017.1376204.

Pool, E., V. Sennwald, S. Delplanque, T. Brosch, and D. Sander. 2016. Measuring wanting and liking from animals to humans: A systematic review. Neurosci. Biobehav. Rev. 63:124-142. https://doi.org/ 10.1016/j.neubiorev.2016.01.006.

Prescott, N. B., T. T. Mottram, and A. J. F. Webster. 1998. Relative motivations of dairy cows to be milked or fed in a Y-maze and an automatic milking system. Appl. Anim. Behav. Sci. 57:23-33. https://doi.org/10.1016/S0168-1591(97)00112-3.

Prkachin, K. M. 1992. The consistency of facial expressions of pain: A comparison across modalities. Pain 51:297-306. https://doi.org/10 .1016/0304-3959(92)90213-U.

Proctor, H., and G. Carder. 2014. Can ear postures reliably measure the positive emotional state of cows? Appl. Anim. Behav. Sci. 161:20-27. https://doi.org/10.1016/j.applanim.2014.09.015.

Proctor, H., and G. Carder. 2016. Can changes in nasal temperature be used as an indicator of emotional state in cows? Appl. Anim. Behav. Sci. 184:1-6. https://doi.org/10.1016/j.applanim.2016.07 013.

Proctor, H. S., and G. Carder. 2015a. Nasal temperatures in dairy cows are influenced by positive emotional state. Physiol. Behav. 138:340-344. https://doi.org/10.1016/j.physbeh.2014.11.011.

Proctor, H. S., and G. Carder. 2015b. Measuring positive emotions in cows: Do visible eye whites tell us anything? Physiol. Behav 147:1-6. https://doi.org/10.1016/j.physbeh.2015.04.011.

Rashotte, M. E. 1979. Reward Training: Methods and Data. M. E. Bitterman, V. M. LoLordo, J. B. Overmier, and M. E. Rashotte, ed. NATO Advanced Study Institutes Series. Springer US, Boston, MA. https://doi.org/10.1007/978-1-4684-3387-6_5

Redbo, I. 1993. Stereotypies and cortisol secretion in heifers subjected to tethering. Appl. Anim. Behav. Sci. 38:213-225. https://doi.org/ 10.1016/0168-1591(93)90020-P.

Reefmann, N., F. Bütikofer Kaszàs, B. Wechsler, and L. Gygax. 2009 Ear and tail postures as indicators of emotional valence in sheep. Appl. Anim. Behav. Sci. 118:199-207. https://doi.org/10.1016/j .applanim.2009.02.013.

Rizk, A., S. Herdtweck, H. Meyer, J. Offinger, A. Zaghloul, and J. Rehage. 2012. Effects of xylazine hydrochloride on hormonal, metabolic, and cardiorespiratory stress responses to lateral recumbency and claw trimming in dairy cows. J. Am. Vet. Med. Assoc. 240:1223-1230.

Rizvi, S. J., D. A. Pizzagalli, B. A. Sproule, and S. H. Kennedy. 2016. Assessing anhedonia in depression: Potentials and pitfalls. Neurosci. Biobehav. Rev. 65:21-35. https://doi.org/10.1016/j.neubiorev .2016.03.004

Roelofs, S., H. Boleij, R. E. Nordquist, and F. J. van der Staay. 2016 Making decisions under ambiguity: Judgment bias tasks for assess- ing emotional state in animals. Front. Behav. Neurosci. 10. https:/ /doi.org/10.3389/fnbeh.2016.00119.

Rushen, J. 1986. Some problems with the physiological concept of "stress". Aust. Vet. J. 63:359-361. https://doi.org/10.1111/j.1751 -0813.1986.tb02896.x.

Rushen, J., A. Boissy, E. M. C. Terlouw, and A. M. B. de Passillé. 1999. Opioid peptides and behavioral and physiological responses of dairy cows to social isolation in unfamiliar surroundings. J. Anim. Sci. 77:2918-2924. https://doi.org/10.2527/1999.77112918x.

Rushen, J., and A. M. de Passillé. 2012. Automated measurement of acceleration can detect effects of age, dehorning and weaning on locomotor play of calves. Appl. Anim. Behav. Sci. 139:169-174. https://doi.org/10.1016/j.applanim.2012.04.011.

Rutter, S. M., R. J. Orr, N. H. Yarrow, and R. A. Champion. 2004. Dietary preference of dairy cows grazing ryegrass and white clover. J. Dairy Sci. 87:1317-1324. https://doi.org/10.3168/jds.S0022 -0302(04)73281-6.

Sandem, A.-I., and B. O. Braastad. 2005. Effects of cow-calf separation on visible eye white and behaviour in dairy cows - $\mathrm{A}$ brief report. Appl. Anim. Behav. Sci. 95:233-239. https://doi.org/10 .1016/j.applanim.2005.04.011.

Sandem, A.-I., B. O. Braastad, and M. Bakken. 2006. Behaviour and percentage eye-white in cows waiting to be fed concentrate- $\mathrm{A}$ brief report. Appl. Anim. Behav. Sci. 97:145-151. https://doi.org/ 10.1016/j.applanim.2005.08.003.

Sandem, A. I., B. O. Braastad, and K. E. Bøe. 2002. Eye white may indicate emotional state on a frustration-contentedness axis in dairy cows. Appl. Anim. Behav. Sci. 79:1-10. https://doi.org/10.1016/ S0168-1591(02)00029-1.

Sandem, A. I., A. M. Janczak, and B. O. Braastad. 2004. A short note on effects of exposure to a novel stimulus (umbrella) on behaviour and percentage of eye-white in cows. Appl. Anim. Behav. Sci. 89:309-314. https://doi.org/10.1016/j.applanim.2004.06.011

Schmied, C., X. Boivin, and S. Waiblinger. 2008. Stroking different body regions of dairy cows: Effects on avoidance and approach behavior toward humans. J. Dairy Sci. 91:596-605. https://doi.org/ $10.3168 /$ jds. $2007-0360$

Schön, P. C., K. Hämel, B. Puppe, A. Tuchscherer, W. Kanitz, and G. Manteuffel. 2007. Altered vocalization rate during the estrous cycle in dairy cattle. J. Dairy Sci. 90:202-206. https://doi.org/10 .3168/jds.S0022-0302(07)72621-8.

Schütz, K., D. Davison, and L. Matthews. 2006. Do different levels of moderate feed deprivation in dairy cows affect feeding motivation? Appl. Anim. Behav. Sci. 101:253-263. https://doi.org/10.1016/j .applanim.2006.02.008.

Schütz, K. E., N. R. Cox, K. A. Macdonald, J. R. Roche, G. A. Verkerk, A. R. Rogers, C. B. Tucker, L. R. Matthews, S. Meier, and J. R. Webster. 2013. Behavioral and physiological effects of a short-term feed restriction in lactating dairy cattle with different body condition scores at calving. J. Dairy Sci. 96:4465-4476. https: //doi.org/10.3168/jds.2012-6507.

Schwartzkopf-Genswein, K. S., J. M. Stookey, A. M. de Passillé, and J. Rushen. 1997a. Comparison of hot-iron and freeze branding on cortisol levels and pain sensitivity in beef cattle. Can. J. Anim. Sci 77:369-374. https://doi.org/10.4141/A96-127.

Schwartzkopf-Genswein, K. S., J. M. Stookey, and R. Welford. 1997b. Behavior of cattle during hot-iron and freeze branding and the effects on subsequent handling ease. J. Anim. Sci. 75:2064-2072.

Sherwin, C. M., and I. S. Olsson. 2004. Housing conditions affect self-administration of anxiolytic by laboratory mice. Anim. Welf. 13:33-38.

Shriver, A. J. 2014. The asymmetrical contributions of pleasure and pain to animal welfare. Camb. Q. Healthc. Ethics 23:152-162. https://doi.org/10.1017/S0963180113000686.

Siegel, P. B., S. J. Gustin, and M. N. Katanbaf. 2011. Motor ability and self-selection of an analgesic drug by fast-growing chickens. J. Appl. Poult. Res. 20:249-252. https://doi.org/10.3382/japr.2009 $-00118$.

Sneddon, L. U. 2018. Comparative physiology of nociception and pain. Physiology (Bethesda) 33:63-73. https://doi.org/10.1152/physiol .00022 .2017 . 
Solano, J., F. Galindo, A. Orihuela, and C. S. Galina. 2004. The effect of social rank on the physiological response during repeated stressful handling in Zebu cattle (Bos indicus). Physiol. Behav. 82:679-683. https://doi.org/10.1016/j.physbeh.2004.06.005.

Solomon, S. E. 1997. Egg \& Eggshell Quality. Iowa State University Press, Ames.

Soltis, J., E. Blowers Tracy, and A. Savage. 2011. Measuring positive and negative affect in the voiced sounds of African elephants (Loxodonta africana). J. Acoust. Soc. Am. 129:1059-1066. https://doi .org/10.1121/1.3531798.

Stafford, K. J., and D. J. Mellor. 2005a. Dehorning and disbudding distress and its alleviation in calves. Vet. J. 169:337-349. https:// doi.org/10.1016/j.tvjl.2004.02.005.

Stafford, K. J., and D. J. Mellor. 2005b. The welfare significance of the castration of cattle: A review. N. Z. Vet. J. 53:271-278. https://doi .org/10.1080/00480169.2005.36560.

Stafford, K. J., and D. J. Mellor. 2011. Addressing the pain associated with disbudding and dehorning in cattle. Appl. Anim. Behav. Sci. 135:226-231. https://doi.org/10.1016/j.applanim.2011.10.018.

Stěhulová, I., L. Lidfors, and M. Spinka. 2008. Response of dairy cows and calves to early separation: Effect of calf age and visual and auditory contact after separation. Appl. Anim. Behav. Sci. 110:144165. https://doi.org/10.1016/j.applanim.2007.03.028.

Stewart, M., K. J. Stafford, S. K. Dowling, A. L. Schaefer, and J. R. Webster. 2008. Eye temperature and heart rate variability of calves disbudded with or without local anaesthetic. Physiol. Behav. 93:789-797. https://doi.org/10.1016/j.physbeh.2007.11.044.

Stewart, M., J. M. Stookey, K. J. Stafford, C. B. Tucker, A. R. Rogers, S. K. Dowling, G. A. Verkerk, A. L. Schaefer, and J. R. Webster. 2009. Effects of local anesthetic and a nonsteroidal antiinflammatory drug on pain responses of dairy calves to hot-iron dehorning. J. Dairy Sci. 92:1512-1519. https://doi.org/10.3168/jds.2008-1578.

Stewart, M., G. A. Verkerk, K. J. Stafford, A. L. Schaefer, and J. R. Webster. 2010. Noninvasive assessment of autonomic activity for evaluation of pain in calves, using surgical castration as a model. J. Dairy Sci. 93:3602-3609. https://doi.org/10.3168/jds.2010-3114.

Stilwell, G., R. C. Carvalho, N. Carolino, M. S. Lima, and D. M. Broom. 2010. Effect of hot-iron disbudding on behaviour and plasma cortisol of calves sedated with xylazine. Res. Vet. Sci. 88:188193. https://doi.org/10.1016/j.rvsc.2009.06.012.

Stilwell, G., M. S. Lima, and D. M. Broom. 2008. Effects of nonsteroidal anti-inflammatory drugs on long-term pain in calves castrated by use of an external clamping technique following epidural anesthesia. Am. J. Vet. Res. 69:744-750. https://doi.org/10.2460/ajvr 69.6.744.

Stock, M. L., S. L. Baldridge, D. Griffin, and J. F. Coetzee. 2013. Bovine dehorning: Assessing pain and providing analgesic management. Vet. Clin. North Am. Food Anim. Pract. 29:103-133. https: //doi.org/10.1016/j.cvfa.2012.11.001.

Stojkov, J., M. A. G. von Keyserlingk, J. N. Marchant-Forde, and D. M. Weary. 2015. Assessment of visceral pain associated with metritis in dairy cows. J. Dairy Sci. 98:5352-5361. https://doi.org/10 $.3168 /$ jds.2014-9296.

Stranahan, A. M., K. Lee, and M. P. Mattson. 2008. Central mechanisms of HPA axis regulation by voluntary exercise. Neuromolecular Med. 10:118-127. https://doi.org/10.1007/s12017-008-8027-0.

Stubsjøen, S. M., A. S. Flø, R. O. Moe, A. M. Janczak, E. Skjerve, P. S. Valle, and A. J. Zanella. 2009. Exploring non-invasive methods to assess pain in sheep. Physiol. Behav. 98:640-648. https://doi .org/10.1016/j.physbeh.2009.09.019.

Sylvester, S. P., K. Stafford, D. Mellor, R. Bruce, and R. Ward. 2004. Behavioural responses of calves to amputation dehorning with and without local anaesthesia. Aust. Vet. J. 82:697-700. https://doi .org/10.1111/j.1751-0813.2004.tb12162.x.

Szechtman, H., P. J. Lambrou, A. R. Caggiula, and E. S. Redgate 1974. Plasma corticosterone levels during sexual behavior in male rats. Horm. Behav. 5:191-200. https://doi.org/10.1016/0018 $-506 \mathrm{X}(74) 90043-9$

Teixeira, D. L., M. J. Hötzel, and L. C. P. Machado Filho. 2006. Designing better water troughs: 2 . Surface area and height, but not depth, influence dairy cows' preference. Appl. Anim. Behav. Sci 96:169-175. https://doi.org/10.1016/j.applanim.2005.06.003.

Telezhenko, E., L. Lidfors, and C. Bergsten. 2007. Dairy cow preferences for soft or hard flooring when standing or walking. J. Dairy Sci. 90:3716-3724. https://doi.org/10.3168/jds.2006-876.

Thomas, T. J., D. M. Weary, and M. C. Appleby. 2001. Newborn and 5 -week-old calves vocalize in response to milk deprivation. Appl. Anim. Behav. Sci. 74:165-173. https://doi.org/10.1016/S0168 $-1591(01) 00164-2$

Thüer, S., S. Mellema, M. G. Doherr, B. Wechsler, K. Nuss, and A. Steiner. 2007. Effect of local anaesthesia on short- and long-term pain induced by two bloodless castration methods in calves. Vet. J. 173:333-342. https://doi.org/10.1016/j.tvjl.2005.08.031.

Travain, T., E. S. Colombo, L. C. Grandi, E. Heinzl, A. Pelosi, E. Prato Previde, and P. Valsecchi. 2016. How good is this food? A study on dogs' emotional responses to a potentially pleasant event using infrared thermography. Physiol. Behav. 159:80-87. https:// doi.org/10.1016/j.physbeh.2016.03.019.

Travain, T., E. S. Colombo, E. Heinzl, D. Bellucci, E. Prato Previde, and P. Valsecchi. 2015. Hot dogs: Thermography in the assessment of stress in dogs (Canis familiaris) - A pilot study. J. Vet. Behav. 10:17-23. https://doi.org/10.1016/j.jveb.2014.11.003.

Treadway, M. T., and D. H. Zald. 2011. Reconsidering anhedonia in depression: Lessons from translational neuroscience. Neurosci. Biobehav. Rev. 35:537-555. https://doi.org/10.1016/j.neubiorev 2010.06.006

Tucker, C. B., D. M. Weary, and D. Fraser. 2004. Free-stall dimensions: Effects on preference and stall usage. J. Dairy Sci. 87:12081216. https://doi.org/10.3168/jds.S0022-0302(04)73271-3.

Tzschentke, T. M. 1998. Measuring reward with the conditioned place preference paradigm: A comprehensive review of drug effects, recent progress and new issues. Prog. Neurobiol. 56:613-672. https:/ /doi.org/10.1016/S0301-0082(98)00060-4.

Van Os, J. M. C., E. M. Mintline, T. J. DeVries, and C. B. Tucker. 2018. Domestic cattle (Bos taurus taurus) are motivated to obtain forage and demonstrate contrafreeloading. PLoS One 13:e0193109. https://doi.org/10.1371/journal.pone.0193109.

Van Reenen, C. G., H. Hopster, J. T. N. Van der Werf, B. Engel, W. G. Buist, R. B. Jones, H. J. Blokhuis, and S. M. Korte. 2009. The benzodiazepine brotizolam reduces fear in calves exposed to a novel object test. Physiol. Behav. 96:307-314. https://doi.org/10 .1016/j.physbeh.2008.10.016.

Veissier, I., and A. Boissy. 2007. Stress and welfare: Two complementary concepts that are intrinsically related to the animal's point of view. Physiol. Behav. 92:429-433. https://doi.org/10.1016/j .physbeh.2006.11.008.

Verkerk, G. A., A. M. Phipps, J. F. Carragher, L. R. Matthews, and K. Stelwagen. 1998. Characterization of milk cortisol concentrations as a measure of short-term stress responses in lactating dairy cows. Anim. Welf. 7:77-86.

Vianna, D. M. L., and P. Carrive. 2005. Changes in cutaneous and body temperature during and after conditioned fear to context in the rat. Eur. J. Neurosci. 21:2505-2512. https://doi.org/10.1111/j $.1460-9568.2005 .04073 . x$

von Borell, E., J. Langbein, G. Després, S. Hansen, C. Leterrier, J. Marchant-Forde, R. Marchant-Forde, M. Minero, E. Mohr, A. Prunier, D. Valance, and I. Veissier. 2007. Heart rate variability as a measure of autonomic regulation of cardiac activity for assessing stress and welfare in farm animals-A review. Physiol. Behav. 92:293-316. https://doi.org/10.1016/j.physbeh.2007.01.007.

von Keyserlingk, M. A. G., A. A. Cestari, B. Franks, J. A. Fregonesi, and D. M. Weary. 2017. Dairy cows value access to pasture as highly as fresh feed. Sci. Rep. 7:44953. https://doi.org/10.1038/ srep44953.

Wagner, K., K. Barth, E. Hillmann, R. Palme, A. Futschik, and S. Waiblinger. 2013. Mother rearing of dairy calves: Reactions to isolation and to confrontation with an unfamiliar conspecific in a new environment. Appl. Anim. Behav. Sci. 147:43-54. https://doi.org/ 10.1016/j.applanim.2013.04.010.

Warriner, A. B., V. Kuperman, and M. Brysbaert. 2013. Norms of valence, arousal, and dominance for 13,915 English lemmas. Be- 
hav. Res. Methods 45:1191-1207. https://doi.org/10.3758/s13428 -012-0314-x.

Watts, J. M., and J. M. Stookey. 1999. Effects of restraint and branding on rates and acoustic parameters of vocalization in beef cattle. Appl. Anim. Behav. Sci. 62:125-135. https://doi.org/10.1016/ S0168-1591(98)00222-6.

Watts, J. M., and J. M. Stookey. 2000. Vocal behaviour in cattle: The animal's commentary on its biological processes and welfare. Appl. Anim. Behav. Sci. 67:15-33. https://doi.org/10.1016/S0168 -1591(99)00108-2.

Weary, D. M., P. Droege, and V. A. Braithwaite. 2017. Chapter 2: Behavioral evidence of felt emotions: Approaches, inferences, and refinements. Pages 27-48 in Advances in the Study of Behavior. M. Naguib, J. Podos, L. W. Simmons, L. Barrett, S. D. Healy and M. Zuk, ed. Academic Press, Cambridge, MA. 10.1016/ bs.asb.2017.02.002.

Weary, D. M., L. Niel, F. C. Flower, and D. Fraser. 2006. Identifying and preventing pain in animals. Appl. Anim. Behav. Sci. 100:6476. https://doi.org/10.1016/j.applanim.2006.04.013.

Webb, L. E., B. Engel, K. van Reenen, and E. A. M. Bokkers. 2017. Barren diets increase wakeful inactivity in calves. Appl. Anim. Behav. Sci. 197:9-14. https://doi.org/10.1016/j.applanim.2017.08 005 .

Webb, L. E., M. B. Jensen, B. Engel, C. G. van Reenen, W. J. J. Gerrits, I. J. M. de Boer, and E. A. M. Bokkers. 2014. Chopped or long roughage: What do calves prefer? Using cross point analysis of double demand functions. PLoS One 9:e88778. https://doi.org/ 10.1371/journal.pone.0088778

Webb, L. E., R. Veenhoven, J. L. Harfeld, and M. B. Jensen. 2019 What is animal happiness? Ann. N. Y. Acad. Sci. 1438:62-76. https://doi.org/10.1111/nyas.13983.

Whalen, P. J., J. Kagan, R. G. Cook, F. C. Davis, H. Kim, S. Polis, D G. McLaren, L. H. Somerville, A. A. McLean, J. S. Maxwell, and T. Johnstone. 2004. Human amygdala responsivity to masked fear- ful eye whites. Science 306:2061. https://doi.org/10.1126/science .1103617 .

Whittlestone, W. G., M. M. Mullord, R. Kilgour, and L. R. Cate. 1975. Electric shocks during machine milking. N. Z. Vet. J. 23:105108. https://doi.org/10.1080/00480169.1975.34209.

Winder, C. B., C. L. Miltenburg, J. M. Sargeant, S. J. LeBlanc, D. B Haley, K. D. Lissemore, M. A. Godkin, and T. F. Duffield. 2018. Effects of local anesthetic or systemic analgesia on pain associated with cautery disbudding in calves: A systematic review and metaanalysis. J. Dairy Sci. 101:5411-5427. https://doi.org/10.3168/jds .2017-14092.

Windschnurer, I., K. Barth, and S. Waiblinger. 2009. Can stroking during milking decrease avoidance distances of cows towards humans? Anim. Welf. 18:507-513.

Wong, K., M. Elegante, B. Bartels, S. Elkhayat, D. Tien, S. Roy, J. Goodspeed, C. Suciu, J. Tan, C. Grimes, A. Chung, M. Rosenberg, S. Gaikwad, A. Denmark, A. Jackson, F. Kadri, K. M. Chung, A. Stewart, T. Gilder, E. Beeson, I. Zapolsky, N. Wu, J. Cachat, and A. V. Kalueff. 2010. Analyzing habituation responses to novelty in zebrafish (Danio rerio). Behav. Brain Res. 208:450-457. https:// doi.org/10.1016/j.bbr.2009.12.023.

Wüst, S., I. S. Federenko, E. F. C. van Rossum, J. W. Koper, and D. H. Hellhammer. 2005. Habituation of cortisol responses to repeated psychosocial stress - Further characterization and impact of genetic factors. Psychoneuroendocrinology 30:199-211. https:// doi.org/10.1016/j.psyneuen.2004.07.002

Zethof, T. J. J., J. A. M. Van Der Heyden, J. T. B. M. Tolboom, and B. Olivier. 1994. Stress-induced hyperthermia in mice: A methodological study. Physiol. Behav. 55:109-115. https://doi.org/10 .1016/0031-9384(94)90017-5.

Zidar, J., I. Campderrich, E. Jansson, A. Wichman, S. Winberg, L. Keeling, and H. Løvlie. 2018. Environmental complexity buffers against stress-induced negative judgement bias in female chickens. Sci. Rep. 8:5404. https://doi.org/10.1038/s41598-018-23545-6. 